\title{
IN SILICO EVALUATION OF ULTRAFILTRATION AND NANOFILTRATION MEMBRANE CASCADES FOR CONTINUOUS FRACTIONATION OF PROTEIN HYDROLYSATE FROM TUNA PROCESSING BY-PRODUCT
}

\author{
R. Abejón ${ }^{1,2 *}$, A. Abejón ${ }^{3}$, A. Garea ${ }^{3}$, T. Tsuru², A. Irabien ${ }^{3}$, M.P. Belleville ${ }^{1}$, J. Sanchez-Marcano ${ }^{1}$ \\ 1 Institut Européen des Membranes (IEM), ENSCM, UM, CNRS - Université de Montpellier, CC 047, Place Eugène Bataillon, \\ 34095 Montpellier, France. \\ 2 Department of Chemical Engineering, Hiroshima University, 1-4-1 Kagayami-yama, Higashi-Hiroshima, Hiroshima 739-8527, \\ Japan \\ 3 Departamento de Ingenierías Química y Biomolecular, Universidad de Cantabria, Avda. Los Castros s/n, 39005 Santander, \\ Cantabria, Spain
}

ricardo.abejon@hotmail.com

\section{Abstract}

The present work proposes the design of cascades that integrate ultrafiltration (UF) and nanofiltration (NF) membranes to separate the different protein fractions from the protein hydrolysate obtained after hydrolysis of tuna by-products. Experimental data (permeate flux and rejection of proteins fractions under different applied pressures) previously obtained and published by this research group were fitted to empirical models, which were the base for a process simulation model. High recovery rates (0.9) in the UF stages implied high process yields by reduced desired fraction losses, while similar recovery rates in the NF stages were required for high product purity. Nevertheless, the applied pressures were not so influent over the performance of the system. Optimization problems were solved to identify the optimal design and operation conditions to maximize the product purity or the process yield. Maximal purity of the preferred $1-4 \mathrm{kDa}$ fraction $(49.3 \%$ from $19.0 \%$ in feed stream) obtained by the configuration with 3 UF stages and other 3 NF stages implied 2 and 5 bar pressures applied in the UF and NF stages respectively, while 0.9 was the optimal recovery rate value for all the stages. These maximal purity conditions resulted in $62.6 \%$ process yield, defined as the percentage of the $1-4 \mathrm{kDa}$ fraction in the feed stream recovered in 
the product stream. Besides, multi-objective optimization of the process was also carried out to obtain the Pareto graphs that represent the counterbalance between maximal yields and purities.

Keywords: Fish protein hydrolysate, Ultrafiltration, Nanofiltration, Fractionation process, Membrane cascades, Optimization

\section{Introduction}

Fish processing by-products can be defined as the fish material left over from primary processing during the fish manufacturing processes. ${ }^{1}$ This definition includes large quantities of substandard muscles, viscera, heads, skins, fins, frames, trimmings, shellfish and crustacean shell wastes. These by-products account generally for a range from 30 to $50 \%$ of the total weight of the starting material, but higher values, as high as $80 \%$, have been identified for specific species and processing options. ${ }^{2,3}$

Until recent times, these by-products have been discarded or only used for the production of animal feeds and the manufacture of organic fertilizers. ${ }^{4}$ However, these options can be characterized by their very low economic value. Therefore, novel alternatives have been explored to transform this undervalued natural resource into more valuable and marketable products improving the sustainable management of fishing industries by avoiding the high cost and environmental problems associated with disposal of such waste material.

Among all the possible applications which have been identified, the recovery of chemical compounds with a "natural" label shows great potentiality and some of them deserve to be mentioned as examples of valuable substances for other segments of the food industry and different industrial sectors: from natural pigments to enzymes, including several other products. ${ }^{5}$ Besides, while fish by-products have been identified as waste resources to be used for energy generation purposes, ${ }^{6-9}$ enzymatic hydrolysis can be considered the most deeply investigated option for the recovery of valuable components from fish by-products, contributing to the upgrading of these protein-rich raw materials by their transformation into biologically active peptides..$^{10-13}$ 
Indeed, besides being relevant sources of nitrogen and amino acids, biologically active peptides have numerous potential physiological functions within the body, including immunomodulatory, hypocholesterolemic, antibacterial, antithrombotic, antihypertensive and antioxidant activity or multifunctional properties, ${ }^{14-19}$ which make them very desirable ingredients for functional foods and pharmaceutical applications. ${ }^{20}$

Enzymatic hydrolysis of proteins normally results in a very complex mixture of numerous peptides with different amino acid sequences and molecular weights from 0.4 to higher than $10 \mathrm{kDa}$ with very different physicochemical properties, such as charge, adsorption characteristics and solubility. However, according to most of the studies, ${ }^{21,22}$ fractions with molecular weight between 1 and $4 \mathrm{kDa}$ have been considered centers of interest for nutritional and pharmaceutical purposes. Consequently, properly selected and designed separation techniques have to be developed to effectively carry out fractionation and purification of high added value molecules from enzymatic hydrolysates. ${ }^{23}$

Chromatographic techniques and $\mathrm{pH}$ precipitation have been extensively proposed for the fractionation of peptides. On the one hand, even if chromatography offers extremely high resolution and even the separation of individual peptides, its application in industrial frameworks is not an economically competitive option because of the high costs. ${ }^{24}$ Other disadvantages of chromatographic techniques have been identified, such as high time-consumption, laborious preparative procedures, possible structural modifications of the peptides and the difficulties for continuous application at high capacity. ${ }^{25-}$ ${ }^{28}$ On the other hand, $\mathrm{pH}$ precipitation fails to achieve the necessary fractionation efficiencies and the obtained products have to be reprocessed (by chromatography for example) to attain the desired characteristics due to low yields and variable purities and concentrations. ${ }^{29-31}$

Membrane technologies have been proved as efficient and ecological processes for the extraction (including concentration, purification and fractionation) of valuable molecules from wastes or byproducts in agro-food industry. ${ }^{32,33}$ Consequently, ultrafiltration (UF) and nanofiltration (NF) could be applied to separate peptides based on their size, charge and hydrophobicity characteristics. For the particular case of fish protein hydrolysates, the development of a fractionation process has not been 
deeply investigated. Indeed, in most of the available works, simple configurations of UF and NF membranes have been employed for analytical purposes. ${ }^{34}$

Despite the promising potential of the employment of membranes technologies for high-resolution fractionations, only a limited success in their implementation into industrial processes can be expected without complete analysis of all the aspects related to their process engineering. For example, the influence of operating parameters on membrane separation efficiency is unfortunately very rarely considered. Besides, most of the times, the proposed process configurations are too simple and unsuitable for carrying out in an effective way the fractionation, particularly in situations where recovery of very pure fractions is desired. Nevertheless, membrane cascades have demonstrated their usefulness as effective configurations to coordinate several separation stages in order to overcome the constraints of limited separation processes based on membranes, as the overall selectivity can be significantly improved. ${ }^{35-38}$ This type of configuration has been widely used for the separation and fractionation of proteins and other biological molecules by membranes technologies, ${ }^{39-42}$ but further efforts to progress in the complete design of industrial-scale installations based on this advanced configuration are still pending.

The aim of this work was to contribute to the development and design of continuous fractionation processing systems which take advantage of the employment of membrane cascades to obtain valuable functional peptide fractions from fish by-product protein hydrolysates. The performance of this type of configurations has not been deeply investigated in such application before. Hence, the main tools provided by process systems engineering, such as simulation and optimization, were applied in a novel approach to carry out a complete analysis of these processes. The work includes a sensitivity analysis of the main operation variables and a technical evaluation, prior to the optimization of the system configuration and the determination of the corresponding optimal values for the process variables in order to optimize both the quality of the obtained product and the yield of the process.

\section{Case study and membrane transport modeling}


The importance of tuna to world fish supply is unquestionable, as the total amount of global tuna catches, above 7 million tons per year, demonstrates. ${ }^{43}$ Taking into account that tuna processing industry generates large amount of solid waste, which can reach 50 to $70 \%$ of the raw material, the consideration of the fractionation of protein hydrolysates from tuna processing by-products as illustrating case study was decided. The main source to obtain data has been a collaborative research work about protein hydrolysates from tuna byproducts between the Institut Européen des Membranes of Montpellier in France and the Laboratory of Materials Science and Environment of the Faculty of Science of Sfax in Tunisia and the derived publications..$^{44-47}$ As representative raw material, an aqueous tuna protein hydrolysate produced at pilot-scale by enzymatic hydrolysis using Alcalase ${ }^{\circledR}$ was selected. Its main physicochemical characteristics can be summarized by these two values: $145 \mathrm{~g} / \mathrm{L}$ of dry matter and 72 $\mathrm{g} / \mathrm{L}$ of protein content. The corresponding protein distribution into five defined fractions is given in Table 1 , where the medium (M) fraction is the most interesting one from the nutraceutical point of view.

Table 1

The experimental results for the separation performance of the two different membranes (UF ceramic membrane with $8 \mathrm{kDa}$ cut-off manufactured by Tami and NF polyethersulfone membrane with $1 \mathrm{kDa}$ cut-off manufactured by Microdyn Nadir) when applied to the fractionation of the protein hydrolysate and the influence of the applied pressure and the total protein concentration over it can be found in bibliography. ${ }^{46}$ These results were adjusted to simple models and the required parameters were calculated in order to be able to simulate the performance of the system by means of membrane transport equations.

The permeate production of the UF membrane as function of the applied pressure is shown in Figure 1. For a defined protein concentration, a linear relationship between applied pressure $(\Delta \mathrm{P})$ and obtained permeate flux $\left(J_{P}\right)$ can be identified. This behavior can be easily explained by direct application of Darcy's law:

$$
\mathrm{J}_{\mathrm{P}}=\mathrm{L}_{\mathrm{P}} \cdot \Delta \mathrm{P}
$$


where $L_{p}$ is the membrane permeability. The equation does not contain osmotic pressure related terms, since the molecular weight of the solutes is larger than several $\mathrm{kDa}$ and the corresponding osmotic pressure may be neglected.

Figure 1

The influence of the protein concentration over the permeate production is not direct. For a fixed applied pressure value, protein content is enhanced while the permeate flux decreases. This fact can be explained by the increased filtration resistance due to the presence of more biomolecules, which implies decay in the membrane permeability. However, the effect of the highest concentrations trends to be less important. Therefore, it was decided to plot the membrane permeability against the protein concentration. The form of the curve invited to consider a quadratic relationship between both variables, and it was confirmed when the protein concentration was replaced by its square root (Figure 1).

This result is not unexpected, since this relationship has been previously recognized in filtration processes by other authors. The drag force in the filtration direction is proportional to the square root of the filtration resistance. ${ }^{48}$ In our case study, the drag force opposed to the solvent permeation, reducing the membrane permeability, and the filtration resistance can be considered proportional to the protein content of the fluid to be filtrated. Therefore, this fact can be formulated in mathematical terms as follows:

$$
\mathrm{L}_{\mathrm{P}}=\mathrm{L}_{\mathrm{P} 0}-\mathrm{K}_{\mathrm{R}}[\mathrm{TP}]^{0.5}
$$

where $L_{P 0}$ is the maximal membrane permeability, [TP] the protein concentration and $K_{R}$ the filtration resistance constant. The membrane permeability may be reduced as a consequence of membrane fouling. However, in this study it was not considered as it was supposed to be under control because of a suitable membrane cleaning and replacement strategy.

Totally analogous results were found for the NF membrane, as it can be observed in Figures 1 and 2, which represent the influence of the applied pressure over the permeate flux and the influence of the protein content (as square root) over the membrane permeability respectively. Once again, Darcy's law 
can be employed to define the permeate flux as a function of the applied pressure and the quadratic relationship reappeared when the filtration resistance was analyzed. The resulting solvent transport parameters were determined for both membranes. On the one hand, the baseline membrane permeability Lpo for the UF membrane was $30.0 \mathrm{~L} / \mathrm{h} \mathrm{m}^{2}$ bar, while the value for the NF membrane was 8.4 $\mathrm{L} / \mathrm{h} \mathrm{m}^{2}$ bar. On the other hand, the filtration resistance constant $\mathrm{K}_{\mathrm{R}}$ for the UF membrane was 1.7 $\mathrm{L}^{1.5 / h} \mathrm{~m}^{2}$ bar $\mathrm{g}^{0.5}$, while the value for the NF membrane was $0.6 \mathrm{~L}^{1.5} / \mathrm{h} \mathrm{m}^{2}$ bar $\mathrm{g}^{0.5}$.

In contrast, the rejection performances of both membranes for the different protein fractions cannot be simulated by the same equation. As it can be observed in Figure 2, which represent the rejections of some of the main fractions (reported as \%) under different pressure conditions by the UF and the NF membranes, very dissimilar trends appeared.

Figure 2

It was clear that the obtained curves (constant, linear and parabolic graphs) were not able to be fit by the same transport equation. Therefore, it was decided to resort to totally empirical functions (compiled in Table 2) to describe the three different types of relationships between applied pressure and resulting rejections.

Table 2

\section{Cascades evaluation}

\subsection{Process modeling}

The proposed membrane cascades integrated membrane modules and mixers. The complete mathematical model that described these systems was formulated as follows by the appropriate equations based on mass balances (total and partial for total protein content and protein fractions as components) and the previously obtained transport equations. 
For the mixers, these were the corresponding mass balances:

$$
\begin{gathered}
\mathrm{F}_{\mathrm{IN} 1}+\mathrm{F}_{\mathrm{IN} 2}=\mathrm{F}_{\mathrm{OUT}} \\
\mathrm{F}_{\mathrm{IN} 1} \cdot[\mathrm{TP}]_{\mathrm{IN} 1}+\mathrm{F}_{\mathrm{IN} 2} \cdot[\mathrm{TP}]_{\mathrm{IN} 2}=\mathrm{F}_{\mathrm{OUT}} \cdot[\mathrm{TP}]_{\mathrm{OUT}} \\
\mathrm{F}_{\mathrm{IN} 1} \cdot \mathrm{M}_{\mathrm{IN} 1}^{\mathrm{i}}+\mathrm{F}_{\mathrm{IN} 2} \cdot \mathrm{M}_{\mathrm{IN} 2}^{\mathrm{i}}=\mathrm{F}_{\mathrm{OUT}} \cdot \mathrm{M}_{\mathrm{OUT}}^{\mathrm{i}}
\end{gathered}
$$

where FIN1 $_{1}$ and Fin2 were the flows of the two streams entering the mixer, Fout the flow of the leaving stream, $[T P] x$ the total protein concentration in the $\mathrm{X}$ stream and $\mathrm{M}_{\mathrm{X}}^{\mathrm{i}}$ the concentration of the i protein fraction in the $X$ stream.

Equivalent mass balances were applied to the membrane modules:

$$
\begin{gathered}
\mathrm{F}_{\mathrm{UP}}=\mathrm{F}_{\text {PERM }}+\mathrm{F}_{\mathrm{RET}} \\
\mathrm{F}_{\mathrm{UP}} \cdot[\mathrm{TP}]_{\mathrm{UP}}=\mathrm{F}_{\text {PERM }} \cdot[\mathrm{TP}]_{\text {PERM }}+\mathrm{F}_{\mathrm{RET}} \cdot[\mathrm{TP}]_{\mathrm{RET}} \\
\mathrm{F}_{\mathrm{UP}} \cdot \mathrm{M}_{\mathrm{UP}}^{\mathrm{i}}=\mathrm{F}_{\mathrm{PERM}} \cdot \mathrm{M}_{\mathrm{PERM}}^{\mathrm{i}}+\mathrm{F}_{\mathrm{RET}} \cdot \mathrm{M}_{\mathrm{RET}}^{\mathrm{i}}
\end{gathered}
$$

where the UP, PERM and RET subscripts represented the feed, permeate and retentate streams respectively.

The two main characteristics of the permeate stream, flow and the corresponding protein fraction concentrations, were calculated taking into account the membrane area (АМЕМВ) of the corresponding stage and the permeability and rejection values:

$$
\begin{gathered}
\mathrm{F}_{\mathrm{PERM}}=\mathrm{A}_{\mathrm{MEMB}} \cdot \mathrm{J}_{\mathrm{P}}=\mathrm{A}_{\mathrm{MEMB}} \cdot\left[\mathrm{L}_{\mathrm{P} 0}-\mathrm{K}_{\mathrm{R}}\left(\frac{[\mathrm{TP}]_{\mathrm{UP}}+[\mathrm{TP}]_{\mathrm{RET}}}{2}\right)^{0.5}\right] \cdot \Delta \mathrm{P} \\
\mathrm{M}_{\mathrm{PERM}}^{\mathrm{i}}=\left(1-\mathrm{R}^{\mathrm{i}}\right) \cdot \mathrm{M}_{\mathrm{UP}}^{\mathrm{i}}
\end{gathered}
$$


The recovery rate of each module Rec was expressed as the ratio between the flows of permeate and feed streams:

$$
\operatorname{Rec}=\frac{\mathrm{F}_{\text {PERM }}}{\mathrm{F}_{\mathrm{UP}}}
$$

The performance of the cascades was described by the definition of two useful parameters. The first one was the purity of the medium product stream, measured as the percentage of the medium protein fraction over the total protein concentration:

$$
\mathrm{X}^{\mathrm{M}}=100 \frac{\mathrm{M}_{\mathrm{MPROD}}^{\mathrm{M}}}{[\mathrm{TP}]_{\mathrm{MPROD}}}
$$

The second parameter was the process yield, defined as the percentage of the medium protein fraction entering the system in the feed stream that was recovered in the medium product stream:

$$
\mathrm{Y}^{\mathrm{M}}=100 \frac{\mathrm{F}_{\mathrm{MPROD}} \cdot \mathrm{M}_{\mathrm{MPROD}}^{\mathrm{M}}}{\mathrm{F}_{\mathrm{FEED}} \cdot \mathrm{M}_{\mathrm{FEED}}^{\mathrm{M}}}
$$

\subsection{Simulation and sensitivity analysis}

The characterization of the most basic fractionation system (an only ultrafiltration stage followed by an only nanofiltration stage as represented in Figure 3 and coded 1UF1NF) was the initial essential step for the design of more complex membrane cascades. In order to evaluate the behavior of this basic system, the two previously defined performance parameters (purity $\mathrm{X}^{\mathrm{M}}$ and yield $\mathrm{Y}^{\mathrm{M}}$ ) were analyzed as functions of the applied pressures and the corresponding recovery rates of the stages.

Figure 3 
ASPEN Custom Modeler was used as simulation software for the evaluation, and as initial values, a feed stream of $200 \mathrm{l} / \mathrm{h}$ was selected, with an initial protein content of $72 \mathrm{~g} / \mathrm{L}$ and a protein fraction distribution according to the figures in Table 1.

The results of the investigation of the influence of both recovery rates over the purity and the yield are shown in Figure 4. When the obtained purity was analyzed, very different roles could be assigned to both variables. On the one hand, the recovery rate of the ultrafiltration stage Rec1 had very little influence over the performance of the system (unimportant to the resulting purity). Nevertheless, on the other hand, the recovery rate of the nanofiltration stage Rec2 determined the final purity: the higher the recovery rate, the higher the purity of the desired fraction in the product stream. High recovery rate values implied large permeate streams, particularly rich in lighter protein fractions, which were removed from the retentate stream, resulting in higher content of the desired medium protein fraction.

Figure 4

The opposite case was found when the yield of the process was analyzed: Rec1 become the dominant variable while Rec2 resulted irrelevant. The importance of the first stage for high yield was obvious: low recovery rates implied most part of the feed stream leaved the system as retentate stream, so the medium protein fraction to be derived to the product stream was greatly reduced. Therefore, high recovery rates in the ultrafiltration stage were clearly necessary to allow the recovery of significant amounts of the most desired protein fraction after the nanofiltration stage.

The Figure 5 shows the influence of the applied pressures over the purity and the yield. As a consequence of a first fast outlook to the axis ranges, it could be concluded that the margins of these variables were clearly lower than the ones corresponding to the recovery rates. A deeper analysis revealed the comparable importance of both applied pressures over the product purity. The heterogeneous relationships of the applied pressures and the corresponding rejection values of each protein fraction resulted in a complex framework difficult to be analyzed in detail, but low pressures in both stages appeared as the most effective conditions to improve the purity. 
Figure 5

Nevertheless, the applied pressure in the nanofiltration stage $\Delta \mathrm{P} 2$ had greater influence over the yield of the process, as the value of the applied pressure in the ultrafiltration stage $\Delta \mathrm{P} 1$ was irrelevant. The graph showed maximal values when $\Delta \mathrm{P} 2$ was around 10 bar, which coincided with situations where the rejection values for the three protein fractions with pressure dependence attained maximal values too.

Two alternative cascades including three stages resulted as a consequence of the addition of an extra stage to the basic 1 UF1NF cascade. On the one hand, the 2UF1NF cascade was obtained when the retentate stream of the initial ultrafiltration stage was employed to feed an additional ultrafiltration stage. On the other hand, the 1UF2NF cascade was obtained when the retentate stream of the nanofiltration stage was employed to feed an additional nanofiltration stage. However, when the simulation of both cascades was carried out, some errors appeared because of high protein contents. As previously expressed in Eq. 2, the membranes permeability depended on the protein content of the corresponding feed stream and for high protein contents the membranes became impermeable (even negative values for the permeability could be derived from Eq.2). In order to avoid these limitations, the inclusion of additional water streams before the additional stages was decided for all the following designed cascades and the comparison of the configurations before and after the introduction of the extra water inlet can be observed in Figure 8 for the 2UF1NF cascade. A value equal to $200 \mathrm{l} / \mathrm{h}$ (identical to the feed stream) was imposed for the flows of all these additional water streams. A simulation of the 1UF2NF configuration can be observed in Figure 6 as illustrating example, including the characteristics of all the streams and membrane stages. Nonetheless, the potentiality of these additional water streams to control the protein concentrations and their influence over the process performance will be object of further investigation. Furthermore, the possibility of an additional membrane cascade stage for in situ recovery of water will be evaluated. ${ }^{49}$

Figure 6

A sensitivity analysis to discuss the influence over the process performance of the design and operation variables of the additional ultrafiltration stage (recovery rate Rec1B and applied pressure $\Delta \mathrm{P} 1 \mathrm{~B}$ ) in the 
2UF1NF cascade was completed. Two different situations were covered by the sensitivity analysis: Figure 7 shows the results when the other two stages were configured for high purity, while the results when the system was configured for high yield were not shown because of their similar appearance.

Figure 7

Both graphs showed very similar trends: the recovery rate demonstrated greater influence over the process performance. The direct relationship between the recovery rate and the process yield was expected because this variable defined the amount of the desired protein fraction not recovered in the first ultrafiltration stage which could permeate and arrive to the nanofiltration stage, avoiding its loss from the system in the heavy stream. Moreover, high recovery ratios had positive influence over the purity of the product. As the heaviest protein fractions $(\mathrm{UH}$ and $\mathrm{H})$ were more effectively retained that the preferred one $(M)$, the permeate of the $1 B$ stage was enriched in the $M$ fraction in relation to the feed stream entering that stage. Therefore, the higher amount of permeate recovered in stage 1B, the higher the purity of the obtained product. The applied pressure in this stage was totally irrelevant for the final yield value. Therefore, the applied pressure was only significant for the product quality: lower pressures improved the purity of the preferred protein fraction in the medium stream. Nevertheless, the recovery rate had more influence over the product purity and high recovery ratios were preferred to obtain purer product.

Additionally, the corresponding sensitivity analysis to discuss the influence over the process performance of the design and operation variables of the additional nanofiltration stage (recovery rate Rec2B and applied pressure $\triangle \mathrm{P} 2 \mathrm{~B}$ ) in the 1UF2NF cascade was also completed.

Once again, two different scenarios were proposed: Figure 8 shows the results obtained when the other system variables took values for a high purity configuration, while the graphs corresponding to a high yield situation were not shown because of their similar appearance.

Figure 8 
For the case of the high purity scenario (Figure 8), the recovery rate was again the most relevant variable. High recovery rate implied higher purity but lower yield. This latter fact could be explained because the medium stream was derived from the retentate stream of this additional stage and, despite the high rejection for the medium protein fraction with values above $80 \%$, high permeate flows involved higher losses of the desired protein fraction leaving in the light stream. This way, a clear conflict between purity and yield appeared, since high values for both parameters could not be obtained simultaneously. Meanwhile, the role of the applied pressure was more complex, as the rejections of some protein fractions depended on it. When an intermediate pressure value (for example 10 bar) was selected, which implied close to maximal rejection percentages, the resulted purity values were lower than the ones corresponding to extreme pressures (low or high) as demonstrated by the valley-shaped surface. However, for the case of the yield, these intermediate values resulted more convenient than the extreme points, especially for high recovery rates. Therefore, once again, the conflict between the two main process parameters was obvious.

After the evaluation of the results of the sensitivity analysis, it was clear that the recovery rate was the dominant variable for both filtration stages. High recovery rates in the UF stages were required to obtain high yields values, but the conflict between purity and yield was characteristic of the NF stages: high recovery rates for high yield, but low values for high purity. The applied pressures were not as relevant as the recovery rates. Nevertheless, extreme pressure values, both low and high ones, in the NF stages increased the purity of the product at the expenses of lower process yield.

\section{Cascades optimization}

As previously explained, the implementation of the proposed simulation model was adequate for the analysis of the behavior of the continuous membrane cascades and the corresponding performance trends. Nevertheless, optimization problems were included to be able to identify the optimal design and operation conditions which would maximize the performance of the separation and purification process. ${ }^{50}$ However, the definition of the optimal performance of the process was not a trivial task as a consequence of the conflicting results obtained for the two main parameters: purity and yield. Therefore, 
the independent maximization of the purity (Eq. 12) or the yield (Eq. 13) was chosen as the formulated objective function to optimize.

All the model variables were expressed in terms of the design and operation variables (recovery rates and applied pressures). Constraints for these independent variables were set. The allowed interval for the recovery rates was defined from 0.1 to 0.9 taking into account that recovery rates close to 1 may cause problems of fouling and concentration polarization, while recovery rate values close to 0 imply very low production rates. ${ }^{35}$ Related to the applied pressures, two different ranges were defined: ultrafiltration modules were imposed to be operated between 2 and 6 bar and nanofiltration ones between 5 and 15 bar. These values were selected to avoid, on the one hand, too low pressures, which may be unproductive; and on the other hand, too high pressures, which may cause fouling or polarization problems. Nonetheless, the selected values assured the operation under safe conditions.

GAMS is a high-level modeling system for mathematical programming and optimization. It consists of a language compiler and a stable of integrated high-performance solvers. GAMS software was selected as optimization tool to manage the resulted programming models using CONOPT3 solver. In mathematical terms, the problem can be formulated in the following way:

$\max Z=f(x)$

$$
\begin{aligned}
\text { s.t. } & h(x)=0 \\
& g(x) \leq 0
\end{aligned}
$$

$x \in \Re^{n}$

$\mathrm{X} \mathrm{L}<\mathrm{X}<\mathrm{XU}$

being $\mathrm{Z}$ the target variable to maximize (purity $\mathrm{X}^{\mathrm{M}}$ or yield $\mathrm{YM}^{\mathrm{M}}$ ), $\mathrm{x}$ the vector of independent continuous variables (applied pressures $\Delta \mathrm{P}$ and recovery rates $\mathrm{Rec}$ ), $\mathrm{h}$ the vector of equality constraint functions, and $w$ the vector of inequality constraint functions.

The main results of the optimization programs were compiled in different tables: the Table 3 included the optimal design and operation conditions for maximal purities and yields of the analyzed membrane 
cascades, the Table 4 showed the main characteristics of the three streams leaving each cascade under optimal conditions and the composition of the three streams leaving each cascade under optimal conditions can be observed in the Table 5 .

Table 3

The maximal purity values ranged from $28.1 \%$ for the simplest $1 \mathrm{UF} 1 \mathrm{NF}$ cascade to $49.3 \%$ for the most complex analyzed (3UF3NF) cascade, while the maximal yield values ranged from $59.9 \%$ for the 1UF1NF cascade to $91.9 \%$ for the 3UF3NF cascade. However, the optimal yield value for the 1UF2NF cascade was even lower than the corresponding to the 1 UF1NF (59.5\% versus $59.9 \%)$. This result was reached by the presence of the extra NF stage, which implied an additional loss of the target fraction in the corresponding permeate stream. Nevertheless, it was clear that the number of UF stages was the most influent variable over the process yield. At least 2 stages were required for yield values above $80 \%$, and more than $90 \%$ was achieved by 3 stages, but the purity values obtained for maximal yield processes were quite low, without values above $22.5 \%$ from the initial $19.0 \%$ baseline.

The analysis of the optimal values of the independent variables, applied pressures and recovery rates, revealed different trends. The applied pressures of the UF stages were equal to 2.0 bar without distinction of the optimization objective (maximal purity or yield) but the optimal applied pressures of the NF stages depended on the objective: 5.0 bar were required to reach maximal purity, but 9.17 bar were required to achieve maximal process yield. In a similar way, the optimal recovery rates of the UF stages were 0.9 for both objectives, while different values appeared for the recovery rates of the NF stages as a function of the selected objective: 0.9 values were optimal for maximal purity and 0.1 values for maximal yield. As a consequence of these low recovery rates, the cascades designed for maximal yield required much less total membrane area (between 3 and 6 times depending on the configuration) than those ones designed for maximal purity. 
Some comments about the flows and protein total concentrations shown in Table 4 should be remarked. The heavy stream characteristics were very similar for all the configurations and did not depend on the optimization objective. The flow was around $20 \mathrm{l} / \mathrm{h}$ and the protein content was high (between 101 and $281 \mathrm{~g} / \mathrm{l})$, so the control of this variable may be an important focus of further attention to avoid operation problems: the higher the number of UF stages in the system, the lower the protein concentration of the heavy stream. The light stream was the other sub-product stream and it was the one with the lowest total protein content, without values above $22.5 \mathrm{~g} / \mathrm{l}$. However, its flow strongly depended on the selected objective: maximal purity implied very high flows in order to wash the light and ultralight fractions out when permeating the NF modules, while maximal yields meant more reduced flows to avoid the loss of the medium fraction throughout the NF modules. Lastly, the characteristics of the desired medium stream were the least stable as they varied as functions of the selected objectives and configurations. Flows and protein contents were similar to ones of the heavy stream when maximal purity was required, but very high flows (especially for the more complex configurations) and low protein concentrations, ranged between 14.6 and $52.6 \mathrm{~g} / \mathrm{L}$, appeared for maximal process yields.

Two new process parameters, $\mathrm{L}^{\mathrm{MH}}$ and $\mathrm{L}^{\mathrm{ML}}$, were defined and included in Table 4 to complete the analysis of the performance of the process in relation to the desired protein fraction $M$, as it was useful to determine the losses of the desired protein fraction in the heavy and light streams:

$$
\begin{aligned}
& \mathrm{L}^{\mathrm{MH}}=100 \frac{\mathrm{F}_{\mathrm{H}} \cdot \mathrm{M}_{\mathrm{H}}^{\mathrm{M}}}{\mathrm{F}_{\mathrm{FEED}} \cdot \mathrm{M}_{\mathrm{FEED}}^{\mathrm{M}}} \\
& \mathrm{L}^{\mathrm{ML}}=100 \frac{\mathrm{F}_{\mathrm{L}} \cdot \mathrm{M}_{\mathrm{L}}^{\mathrm{M}}}{\mathrm{F}_{\mathrm{FEED}} \cdot \mathrm{M}_{\mathrm{FEED}}^{\mathrm{M}}}
\end{aligned}
$$

These loss values helped to identify the relevance of the number of each type of membrane. On the one hand, the presence of a higher number of ultrafiltration stages increased the yield of the process by reducing the loss corresponding to the heavy stream. On the other hand, more nanofiltration stages implied higher loss in the light stream, especially when the product purity was maximized. 


\section{Table 5}

The composition of the heavy stream leaving the cascades (very rich in the ultrahigh fraction) did not depend on the objective of the optimization as the design and operation conditions of the UF stages were similar for both cases, but the optimization target was very significant for the other two streams (Table 5). When maximal purity was desired, the medium stream was rich in the medium protein fraction and it was the main fraction in this stream for the 2UF2NF and 3UF3NF cascades. However, when maximal yield was required, the light and ultralight fractions became dominant in the product stream, with contents above 33 and $42 \%$ respectively.

Taking into consideration the impossibility of simultaneous maximal values for the two main parameters of the process, purity and yield, additional investigation was carried out. This way, Pareto diagrams which inter-related both parameters were obtained. A point in these Pareto frontiers corresponds to the maximal feasible purity for a fixed yield and vice versa (the maximal feasible yield for a fixed purity). This case study of multi-objective optimization was solved by application of the epsilon constraint method, which tackles multi-objective optimization problems by solving a series of single objective subproblems, where all the objectives but one, are transformed into constraints. ${ }^{51,52}$

The Pareto diagrams which resulted from maximizing simultaneously the product purity and the process yield of each cascade are depicted in Figure 9. The resulted Pareto frontiers exhibited quasi-linear shapes, with only small curvatures in their central zone. The optimal values shown in Table 3 (maximal purity and yield conditions) correspond to the extreme points of the curves in Figure 9. Although each point in these curves is related with different values of applied pressures and recovery rates (and corresponding membrane areas), general trends can be easily identified. While the operation conditions in the UF stages maintained constant (applied pressures were equal to 2.00 bar and the recovery ratios 0.9), the optimal applied pressure in the NF stages moved from 5.00 bar for maximal purity to 9.71 bar for maximal yield and, in a similar way, the recovery rates varied from 0.9 (maximal purity) to 0.1 (maximal yield). 
When the cascades which incorporated 3 stages (2UF1NF and 1UF2NF) were compared to the base 1UF1NF cascade with 2 stages, different types of performance improvements were identified. On the one hand, if the additional stage was an UF one, the process yield could be highly improved, but the purity interval did not change (Pareto diagram moved upwards). On the other hand, if the additional stage was a NF one, the purity interval was greatly increased and higher values were possible, but the process yield was not improved (Pareto diagram extended rightwards). The simultaneous addition of both types of stages, for example, from 1UF1NF to 2UF2NF or from 2UF2NF to 3UF3NF, implied the improvement of both parameters and higher purity and yield values could be attained (Pareto diagram moved upwards and extended rightwards).

\section{Conclusions}

The recovery of chemical compounds from fish processing by-products has high potentiality, but proper separation processes must be proposed. UF and NF membrane cascades can be applied to separate protein fractions from the very complex mixture obtained after enzymatic hydrolysis of tuna by-products.

A simulation model, based on the empirical equations for solvent and solute transport through the membranes and the mass balances was formulated to represent the process and sensitivity analyses were performed to evaluate the performance of the systems. The influence of the applied pressures and recovery rates over the purity and the yield was investigated. High recovery rates in the UF stages were required to obtain high yields values, but the conflict between purity and yield was characteristic of the NF stages: high recovery rates for high yield, but low values for high purity. The applied pressures were not as relevant as the recovery rates. Nevertheless, extreme pressure values, both low and high ones, in the NF stages increased the purity of the product at the expenses of lower process yield.

Optimization problems were included to be able to identify the optimal design and operation conditions which would maximize the performance of the separation and purification process. The independent maximization of the purity or the yield was chosen as the formulated objective function to optimize. The 
maximal purity values ranged from $28.1 \%$ for the 1 UF1NF cascade to $49.3 \%$ for the 3 UF3NF cascade, while the maximal yield values ranged from $59.9 \%$ for the 1 UF1NF cascade to $91.9 \%$ for the 3 UF 3 NF cascade.

Multi-objective optimization of the process was also carried out. For this purpose, Pareto diagrams were used to interrelate the two main variables: the purity of the desired protein fraction and the process yield. From these Pareto sets of solutions, the maximal yield which can be reached for a specific target purity can be easily identified. The opposite case, the maximal purity which can be reached for a specific target yield, could not be easily justified, as the purity derived from high yield values was very small.

Nevertheless, final purity and yield cannot be considered as limiting restrictions, since higher values for both variables can be obtained after implementation of additional UF and NF stages in the process. Therefore, the corresponding economic considerations will determine the competitiveness of the process. Consequently, further work is planned in order to advance in the viability analysis, in both technical and economic terms, of the proposed process to this innovative application, as well as the consideration of environmental aspects of the process, mainly related to the consumption of fresh water.

\section{Acknowledgements}

R. Abejón acknowledges the assistance of Japan Society for Promotion of Science (JSPS) for the award of a Post-Doctoral Fellowship (Short-Term) for North American and European Researchers (PE14057).

\section{References}

(1) He, S.; Franco, C.; Zhang, W. Process optimisation and physicochemical characterisation of enzymatic hydrolysates of proteins from co-products of Atlantic Salmon (Salmo salar) and Yellowtail Kingfish (Seriola lalandi). Int. J. Food Sci. Technol. 2012, 47, 2397-2404. 
(2) Bechtel, P.J. Properties of different fish processing by-products from pollock, cod and salmon. J. Food Process. Preserv. 2003, 27,101-116.

(3) Bougatef, A.; Nedjar-Arroume, N.; Ravallec-Plé, R.; Leroy, Y.; Guillochon, D.; Barkia, A.; Nasri, M. Angiotensin I-converting enzyme (ACE) inhibitory activities of sardinelle (Sardinella aurita) byproducts protein hydrolysates obtained by treatment with microbial and visceral fish serine proteases. Food Chem. 2008, 111, 350-356.

(4) Arvanitoyannis, I.S.; Kassaveti, A. Fish industry waste: treatments, environmental impacts, current and potential uses. Int. J. Food Sci. Technol. 2008, 43, 726-745.

(5) Jayathilakan, K.; Sultana, K.; Radhakrishna, K.; Bawa, A.S. Utilization of byproducts and waste materials from meat, poultry and fish processing industries: a review. J. Food Sci. Technol. 2012, 49, 278-293.

(6) Navickas, K.; Venslauskas, K.; Petrauskas, A.; Zuperka, V.; Nekrosius, A. Biogas yields from food waste. Eng. Rural Dev. 2013, 12, 417-422.

(7) Altun, Ş.; Lapuerta, M. Properties and emission indicators of biodiesel fuels obtained from waste oils from the Turkish industry. Fuel 2014, 128, 288-295.

(8) García-Moreno, P.J.; Khanum, M.; Guadix, A.; Guadix, E.M. Optimization of biodiesel production from waste fish oil. Renew. Energy 2014, 68, 618-624.

(9) Solli, L.; Bergersen, O.; Sørheim, R.; Briseid, T. Effects of a gradually increased load of fish waste silage in co-digestion with cow manure on methane production. Waste Manag. 2014, 34, 1553-1559.

(10) Picot, L.; Ravallec, R.; Fouchereau-Péron, M.; Vandanjon, L.; Jaouen, P.; Chaplain-Derouiniot, M.; Gúerard, F.; Chabeaud, A.; LeGal, Y.; Martinez Alvarez, O.; Bergé, J.P.; Piot, J.M.; Batista, I.; Pires, C.; Thorkelsson, G.; Delannoy, C.; Jakobsen, G.; Johansson, I.; Bourseaud, P. Impact of ultrafiltration and nanofiltration of an industrial fish protein hydrolysate on its bioactive properties. J. Sci. Food Agric. 2010, 90, 1819-1826.

(11) Sampath Kumar, N.S.; Nazeer, R.A.; Jaiganesh, R. Purification and identification of antioxidant peptides from the skin protein hydrolysate of two marine fishes, horse mackerel (Magalaspis cordyla) and croaker (Otolithes ruber). Amino Acids 2012, 42, 1641-1649.

(12) Pires, C.; Clemente, T.; Batista, I. Functional and antioxidative properties of protein hydrolysates from Cape hake by-products prepared by three different methodologies. J. Sci. Food Agric. 2013, 93, 771-780. 
(13) Rodríguez Amado, I.; Vázquez, J.A.; González, M.P.; Murado, M.A. Production of antihypertensive and antioxidant activities by enzymatic hydrolysis of protein concentrates recovered by ultrafiltration from cuttlefish processing wastewaters. Biochem. Eng. J. 2013, 76, 43-54.

(14) Yamamoto, N.; Ejiri, M.; Mizuno, S. Biogenic peptides and their potential use. Curr. Pharm. Des. 2003, 9, 1345-1355.

(15) Harnedy, P.A.; FitzGerald, R.J. Bioactive peptides from marine processing waste and shellfish: A review. J. Funct. Food 2012, 4, 6-24.

(16) Udenigwe, C.C.; Aluko, R.E. Food protein-derived bioactive peptides: Production, processing, and potential health benefits. J. Food Sci. 2013, 71, R11-R24.

(17) Pérez-Vega, J.A.; Olivera-Castillo, L.; Gómez-Ruiz, J.A.; Hernández-Ledesma, B. Release of multifunctional peptides by gastrointestinal digestion of sea cucumber (Isostichopus badionotus). J. Funct. Food 2013, 5, 869-877.

(18) Centenaro, G.S.; Salas-Mellado, M.; Pires, C.; Batista, I.; Nunes, M.L.; Prentice, C. Fractionation of protein hydrolysates of fish and chicken using membrane ultrafiltration: investigation of antioxidant activity. Appl. Biochem. Biotechnol. 2014, 172, 2877-2893.

(19) Park, S.Y.; Ahn, C.B.; Je, J.Y. Antioxidant and anti-inflammatory activities of protein hydrolysates from Mytilus edulis and ultrafiltration membrane fractions, J. Food Biochem. 2014, 38, 460468.

(20) Lordan, S.; Ross, R.P.; Stanton, C. Marine bioactives as functional food ingredients: Potential to reduce the incidence of chronic diseases. Mar. Drug 2011, 9, 1056-1100.

(21) Segura-Campos, M.R.; Peralta-González, F.; Castellanos-Ruelas, A.; Chel-Guerrero, L.A.; Betancur-Ancona, D.A. Effect of Jatropha curcas peptide fractions on the angiotensin I-converting enzyme inhibitory activity. BioMed Res. Int. 2013, Article ID 541947.

(22) Nwachukwu, I.D.; Girgih, A.T.; Malomo, S.A.; Onuh, J.O.; Aluko, R.E. Thermoase-derived flaxseed protein hydrolysates and membrane ultrafiltration peptide fractions have systolic blood pressure-lowering effects in spontaneously hypertensive rats. Int. J. Mol. Sci. 2014, 15, 18131-18147.

(23) Leeb, E.; Holder, A.; Letzel, T.; Cheison, S.C.; Kulozik, U.; Hinrichs, J. Fractionation of dairy based functional peptides using ion-exchange membrane adsorption chromatography and cross-flow electro membrane filtration. Int. Dairy J. 2014, 38, 116-123. 
(24) Azevedo, A.M.; Rosa, P.A.J.; Ferreira, I.F.; Aires-Barros, M.R. Chromatography-free recovery of biopharmaceuticals through aqueous two-phase processing. Trends Biotechnol. 2009, 27, 240-247.

(25) Mayolo-Deloisa, K.; González-Valdez, J.; Guajardo-Flores, D.; Aguilar, O.; Benavides, J.; RitoPalomares, M. Current advances in the non-chromatographic fractionation and characterization of PEGylated proteins. J. Chem. Technol. Biotechnol. 2011, 86, 18-25.

(26) Galindo-López, M.; Rito-Palomares, M. Practical non-chromatography strategies for the potential separation of PEGylated RNase A conjugates. J. Chem. Technol. Biotechnol. 2013, 88, 4954.

(27) Masuyama, K.; Yamamoto, K.; Ito, K.; Kitagawa, E.; Yamaki, K. Simplified methods for purification of peanut allergenic proteins: Ara h 1, Ara h 2, and Ara h 3. Food Sci. Technol. Res. 2014, $20,875-881$

(28) Muendges, J.; Stark, I.; Mohammad, S.; Górak, A.; Zeiner, T. Single stage aqueous two-phase extraction for monoclonal antibody purification from cell supernatant. Fluid Phase Equilibr. 2015, 385, 227-236

(29) Zhang X.; Qiu, N.; Geng, F.; Ma, M. Simply and effectively preparing high-purity phosvitin using polyethylene glycol and anion-exchange chromatography. J. Sep. Sci. 2011, 34, 3295-3301.

(30) Geng, F.; Huang, X.; Yan, N.; Jia, L.; Ma, M. Purification of hen egg white ovomacroglobulin using one-step chromatography. J. Sep. Sci. 2013, 36, 3717-3722.

(31) Power, O.; Fernández, A.; Norris, R.; Riera, F.A.; FitzGerald, R.J. Selective enrichment of bioactive properties during ultrafiltration of a tryptic digest of $\beta$-lactoglobulin. J. Funct. Food. 2014, 9, $38-47$

(32) Buonomenna, M.G. Membrane processes for a sustainable industrial growth. RSC Adv. 2013, 3, 5694-57.

(33) Szekely, G.; Jimenez-Solomon, M.F.; Marchetti, P.; Kim J.F.; Livingston, A.G. Sustainability assessment of organic solvent nanofiltration: from fabrication to application. Green Chem. 2014, 16, 4440-4473.

(34) Chabeaud, A.; Vandanjon, L.; Bourseau, P.; Jaouen, P.; Chaplain-Derouiniot, M.; Guerard, F. Performances of ultrafiltration membranes for fractionating a fish protein hydrolysate: Application to the refining of bioactive peptidic fractions. Sep. Purif. Technol. 2009, 66, 463-471. 
(35) Abejón, R.; Garea, A.; Irabien, A. Integrated countercurrent reverse osmosis cascades for hydrogen peroxide ultrapurification. Comp. Chem. Eng. 2012, 41, 67-76.

(36) Abejón, R.; Garea, A.; Irabien, A. Optimum design of reverse osmosis systems for hydrogen peroxide ultrapurification. AIChE J. 2012, 58, 3718-3730.

(37) Abejón, R.; Garea, A.; Irabien, A. Analysis and optimization of continuous organic solvent nanofiltration by membrane cascade for pharmaceutical separation. AIChE J. 2014, 60, 931-948.

(38) Kim, J.F.; Szekely, G.; Valtcheva, I.B.; Livingston, A.G. Increasing the sustainability of membrane processes through cascade approach and solvent recovery - pharmaceutical purification case study. Green Chem. 2014, 16, 133-145.

(39) Ghosh, R. Novel cascade ultrafiltration configuration for continuous, high-resolution proteinprotein fractionation: a simulation study. J. Memb. Sci. 2003, 226, 85-99.

(40) Mayani, M.; Mohanty, K.; Filipe, C.; Ghosh, R. Continuous fractionation of plasma proteins HSA and HIgG using cascade ultrafiltration systems. Sep. Purif. Technol. 2009, 70, 231-241.

(41) Arunkumar, A.; Etzel, M.R. Fractionation of alfa-lactalbumin from beta-lactoglobulin using positively charged tangential flow ultrafiltration membranes. Sep. Purif. Technol. 2013, 105, 121-128.

(42) Patil, N.V.; Janssen, A.E.M.; Boom, R.M. Separation of whey proteins using cascaded ultrafiltration. Sep. Sci. Technol. 2014, 49, 2280-2288.

(43) FAO, Year book of fishery statistics; Food and Agricultural Organisation of the United Nations: Rome, 2012.

(44) Saidi, S. Valorisation des co-produits issus des industries de la pêche par hydrolyse enzymatique couplée au fractionnement par procédés membranaires. Application aux co-produits de thon [Valorization of the by-products obtained by the fishing industry by enzymatic hydrolysis coupled to fractionation by membrane processes. Application to the tuna by-products]; PhD Thesis: Sfax, 2013.

(45) Saidi, S.; Belleville, M.P.; Deratani, A.; Ben Amar, R. Optimization of peptide production by enzymatic hydrolysis of tuna dark muscle by-product using commercial proteases. Afr. J. Biotechnol. 2013, 12, 1533-1547.

(46) Saidi, S.; Deratani, A.; Ben Amar, R.; Belleville, M.P. Fractionation of a tuna dark muscle hydrolysate by a two-step membrane process. Sep. Purif. Technol. 2013, 108, 28-36. 
(47) Saidi, S.; Deratani, A.; Belleville, M.P.; Ben Amar, R. Production and fractionation of tuna byproduct protein hydrolysate by ultrafiltration and nanofiltration: Impact on interesting peptides fractions and nutritional properties. Food. Res. Int. 2014, 65, 453-461.

(48) Hwang, K.J.; Tsai, H.Y.; Chen, S.T. Enzymatic hydrolysis suspension cross-flow diafiltration using polysulfone hollow fiber module. J. Memb. Sci. 2014, 454, 418-425.

(49) Kim, J.F.; Szekely, G.; Schaepertoens, M.; Valtcheva, I.B.; Jimenez-Solomon, M.F.; Livingston, A.G. In situ solvent recovery by organic solvent nanofiltration. ACS Sustainable Chem. Eng. 2014, 2, 2371-2379.

(50) Abejón, R.; Garea, A.; Irabien, A. Membrane process optimization for hydrogen peroxide ultrapurification. Comp. Aided Chem. Eng. 2011, 29, 678-682.

(51) Abejón, R.; Garea, A.; Irabien, A. Multiobjective optimization of membrane processes for chemicals ultrapurification. Comp. Aided Chem. Eng. 2012, 30, 542-546.

(52) Abejón, R.; Abejón, A.; Biasi, P.; Gemo, N.; Garea, A.; Salmi, T.; Irabien, A. Hydrogen peroxide obtained via direct synthesis as alternative raw material for ultrapurification process to produce electronic grade chemical. J. Chem. Technol. Biotechnol. 2016, 91, 1136-1148. 


\section{NOMENCLATURE}

AMEMB Membrane area $\left(\mathrm{m}^{2}\right)$

Fs Flow of the $S$ stream $(L / h)$

$J_{P} \quad$ Permeate flux $\left(\mathrm{L} / \mathrm{h} \mathrm{m}^{2}\right)$

$\mathrm{K}_{\mathrm{R}} \quad$ Filtration resistance constant $\left(\mathrm{L}^{1.5} / \mathrm{h} \mathrm{m}^{2}\right.$ bar $\left.\mathrm{g}^{0.5}\right)$

$\mathrm{L}^{\mathrm{MH}} \quad$ Medium protein loss in the heavy stream (\%)

LML Medium protein loss in the light stream (\%)

LP Membrane permeability (L/h $\mathrm{m}^{2}$ bar)

LPO Baseline membrane permeability ( $\mathrm{L} / \mathrm{h} \mathrm{m}^{2}$ bar)

$M_{S}^{i} \quad$ Concentration of $i$ protein fraction in the $S$ stream $(\mathrm{g} / \mathrm{L})$

$R^{i} \quad$ Rejection coefficient (-)

Rec Recovery rate (-)

[TP] Total protein content $(\mathrm{g} / \mathrm{L})$

$[T P]_{S}$ Total protein concentration in the $S$ stream $(g / L)$

$X^{M} \quad$ Purity of the $M$ protein fraction in the medium stream (\%)

$\mathrm{YM}^{\mathrm{M}} \quad$ Process yield (\%)

$\Delta \mathrm{P} \quad$ Applied pressure (bar)

Subscripts (streams)

FEED System feed stream

H Heavy stream

IN1 Mixer inlet stream 1

IN2 Mixer inlet stream 2

L $\quad$ Light stream

MPROD Medium stream

out Mixer outlet stream

UP Module feed stream 
PERM Module permeate stream

RET Module retentate stream

Superscripts (protein fractions)

$\mathrm{H} \quad$ Heavy protein fraction

L Light protein fraction

M Medium protein fraction

UH Ultra-high protein fraction

UL Ultra-light protein fraction 


\section{CAPTIONS}

Table 1. Composition of the protein hydrolysate from tuna processing by-products.

Table 2. Modeled percentual rejections as functions of applied pressure $\Delta \mathrm{P}$ (bar).

Table 3. Summary chart with optimal conditions for maximal purities and yields of the analyzed membrane cascades.

Table 4. Main characteristics of the three streams leaving each cascade under optimal conditions.

Table 5. Composition of the three streams leaving each cascade under optimal conditions. 
Figure 1. a) Experimental influence of applied pressure over permeate flux for UF and NF membranes $([T P]=10 \mathrm{~g} / \mathrm{L})$ and obtained results by application of the calculated model parameters. b) Experimental influence of protein concentration (as square root) over permeate flux for UF ( $\Delta \mathrm{P}=2$ bar) and NF $(\Delta \mathrm{P}=$ 10 bar) membranes and obtained results by application of the calculated model parameters. All the experimental data are taken from Reference [47].

Figure 2. a) Experimental percentual rejections of some protein fractions by UF membrane under different applied pressures $([T P]=10 \mathrm{~g} / \mathrm{L}$ ) and obtained results by application of the proposed model and parameters in Table 2. b) Experimental percentual rejections of some protein fractions by NF membrane under different applied pressures. ([TP] $=10 \mathrm{~g} / \mathrm{L})$ and obtained results by application of the proposed model and parameters in Table 2. All the experimental data are taken from Reference [47]

Figure 3. General schemes of the membrane cascades: a) Scheme of a two-stage (1UF1NF) cascade. b) Scheme of a three-stage (2UF1NF) cascade without additional water inlet. c) Scheme of a threestage (2UF1NF) cascade with additional water inlet. d) Scheme of a three-stage (1UF2NF) cascade.

Figure 4. Dependence relation of the recovery rates (Rec1 and Rec2) over the purity and the yield in a two-stage (1UF1NF) cascade $(\Delta \mathrm{P} 1=4$ bar and $\Delta \mathrm{P} 2=10$ bar $)$.

Figure 5. Dependence relation of the applied pressures $(\Delta \mathrm{P} 1$ and $\Delta \mathrm{P} 2)$ over the purity and the yield in a two-stage $(1 \mathrm{UF} 1 \mathrm{NF})$ cascade $(\operatorname{Rec} 1=0.9$ and $\operatorname{Rec} 2=0.5)$.

Figure 6. Simulation results of a 1UF2NF cascade with additional water inlet.

Figure 7. Dependence relation of the operation variables of the extra stage (Rec1B and $\Delta \mathrm{P} 1 \mathrm{~B})$ over the purity and the yield in a three-stage (2UF1NF) cascade when the other two stages are configured for high purity $(\operatorname{Rec} 1=0.9$ and $\operatorname{Rec} 2=0.9$ and $\Delta \mathrm{P} 1=2$ bar and $\Delta \mathrm{P} 2=5$ bar $)$. 
Figure 8. Dependence relation of the operation variables of the extra stage (Rec2B and $\triangle \mathrm{P} 2 \mathrm{~B})$ over the purity and the yield in a three-stage (1UF2NF) cascade when the other two stages are configured for high purity $(\operatorname{Rec} 1=0.9$ and $\operatorname{Rec} 2=0.9$ and $\Delta \mathrm{P} 1=2$ bar and $\Delta \mathrm{P} 2=5$ bar $)$.

Figure 9. Pareto graphs resulted from the multi-objective optimization process of the different analyzed membrane cascades. 
a)

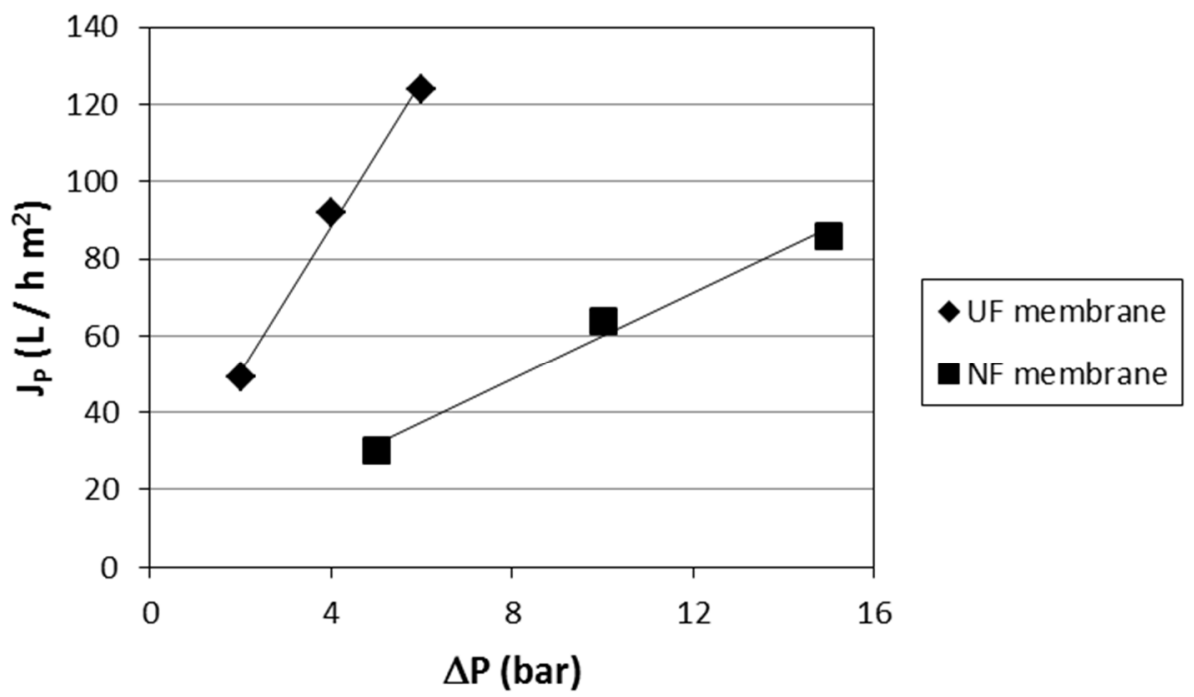

b)

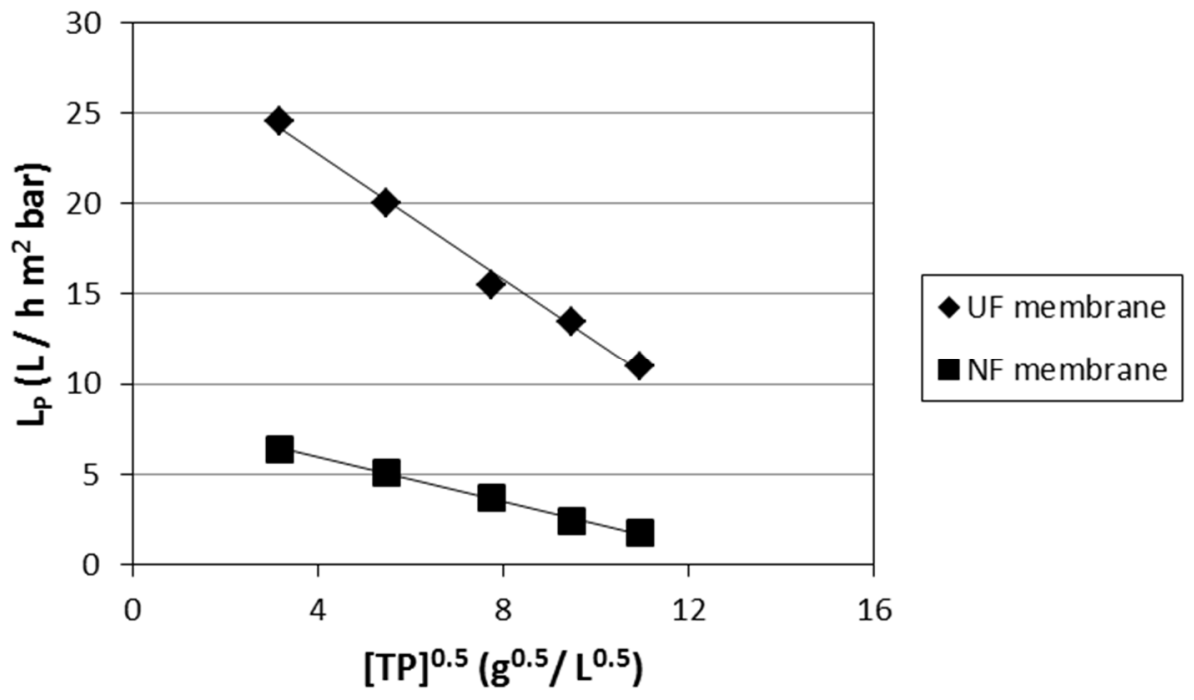

Figure 1 
a)

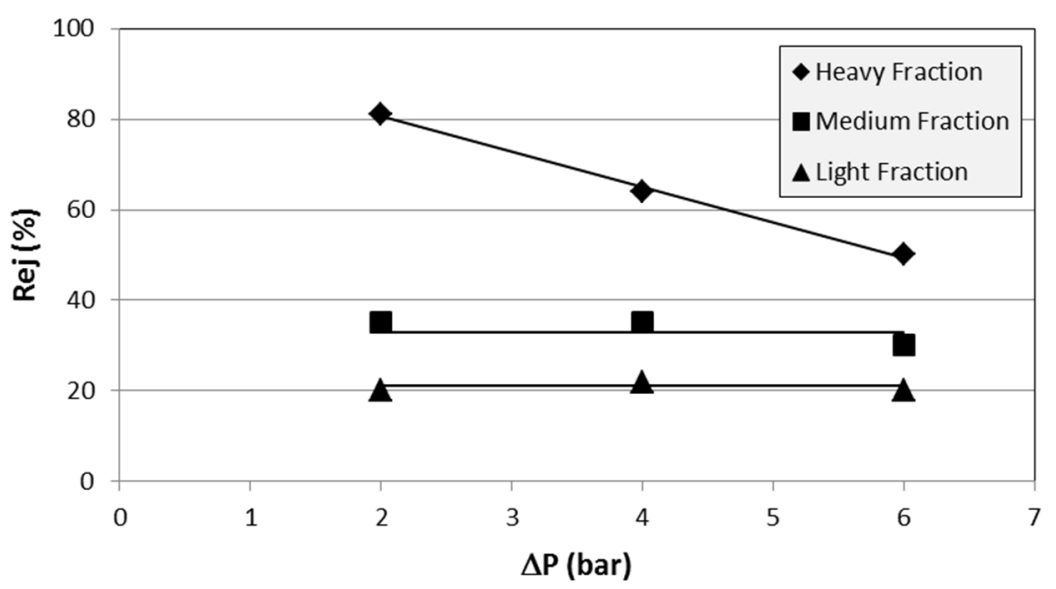

b)

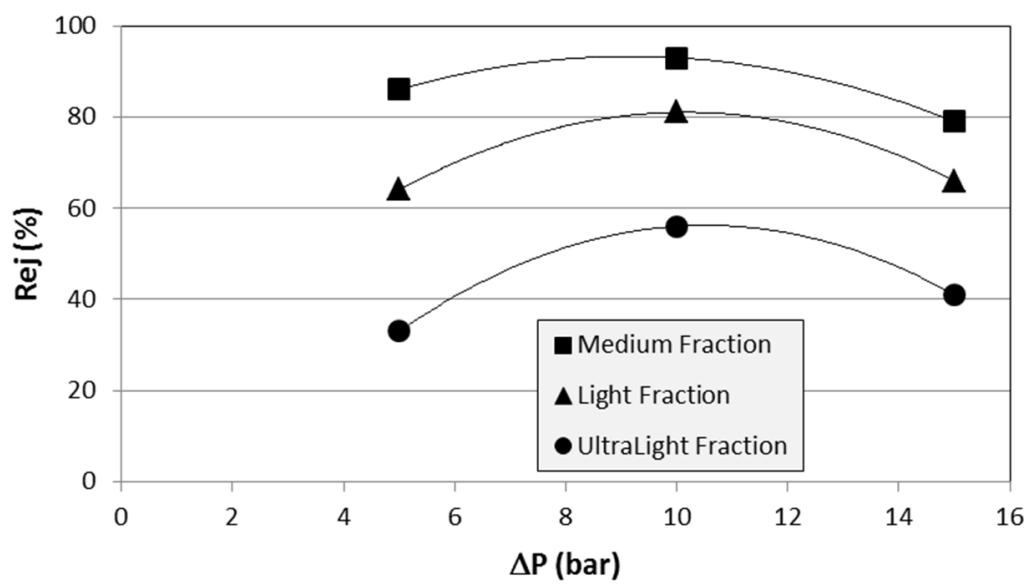

Figure 2 


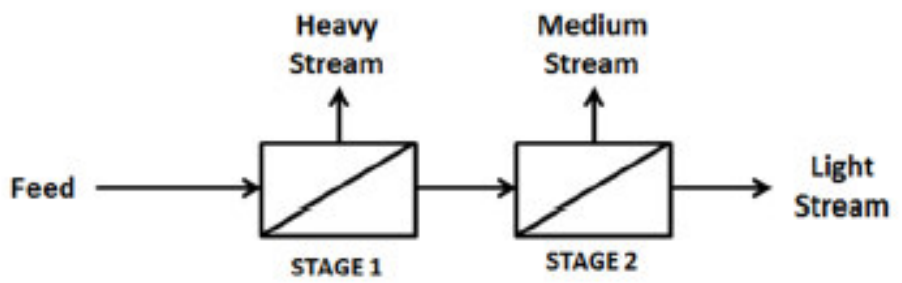

c)

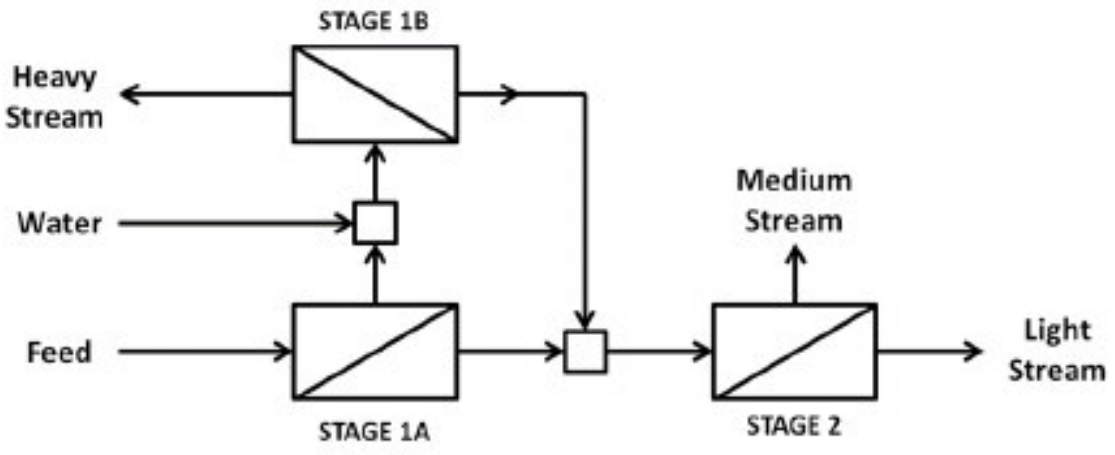

b)

2UF1NF cascade (without water inlet)

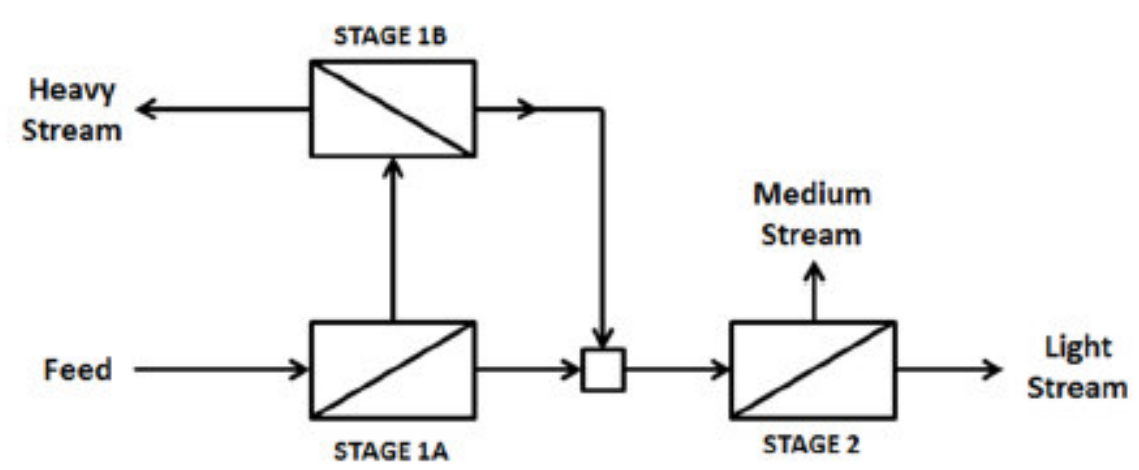

d)

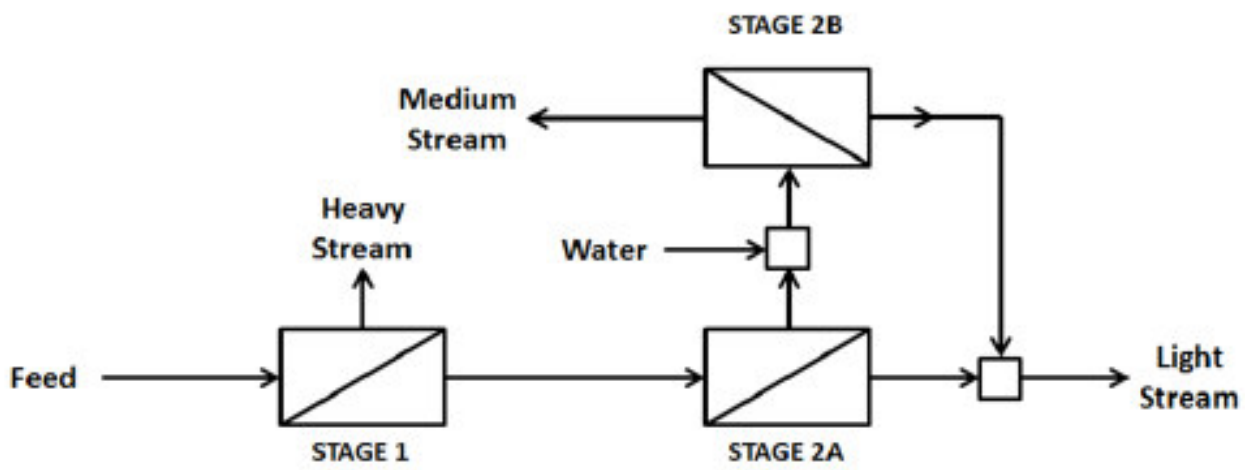

Figure 3 

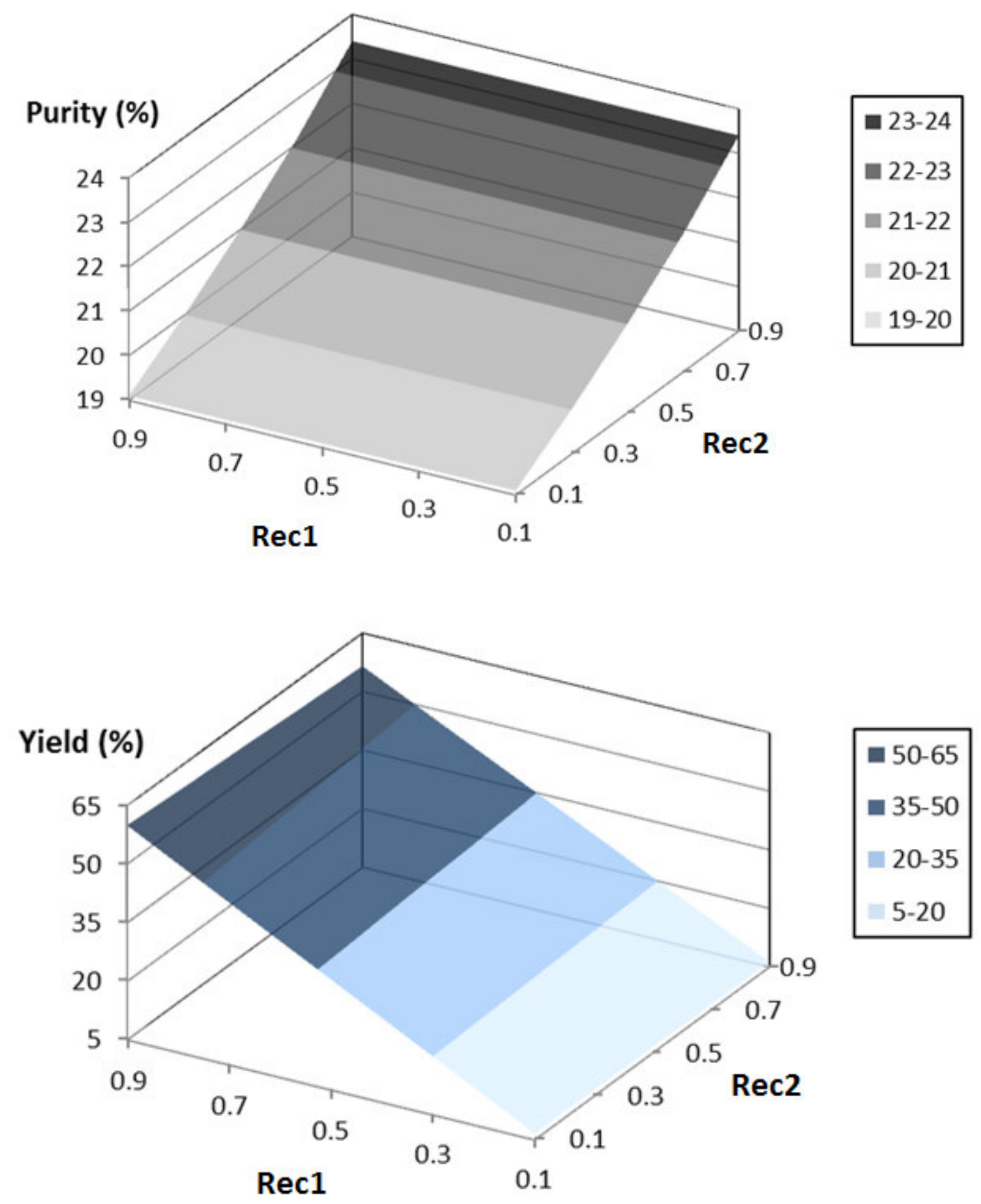

Figure 4 

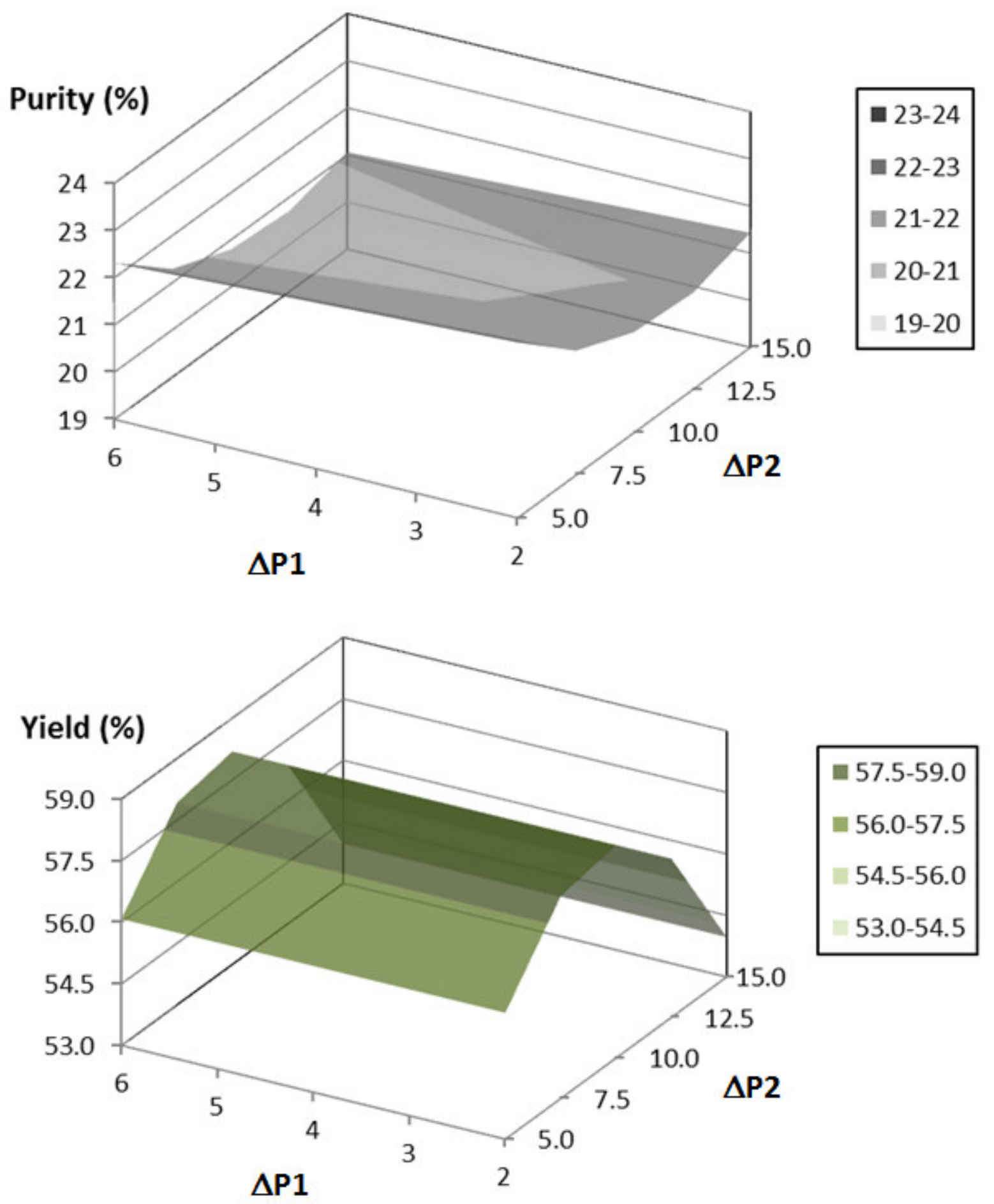

Figure 5 


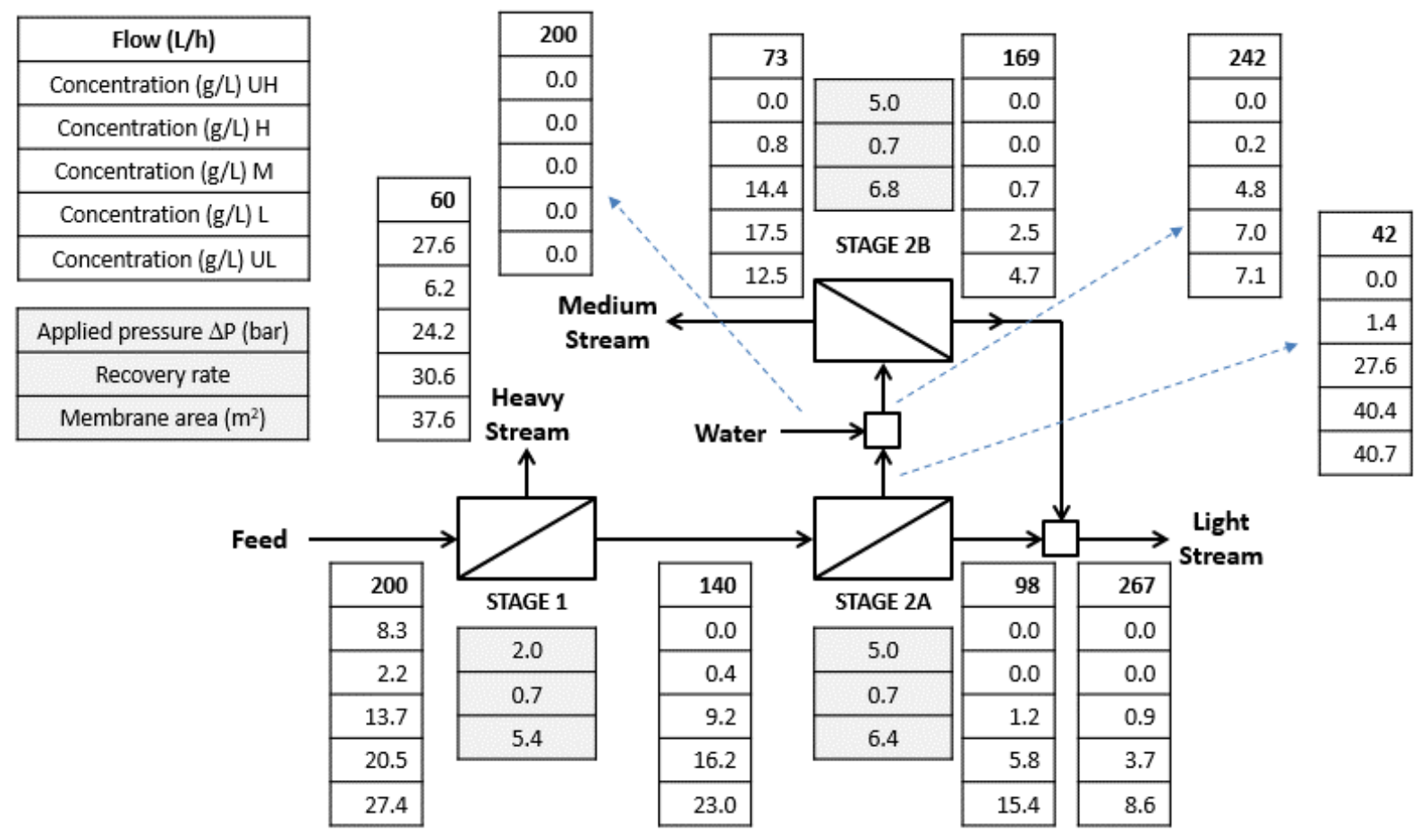

Figure 6 

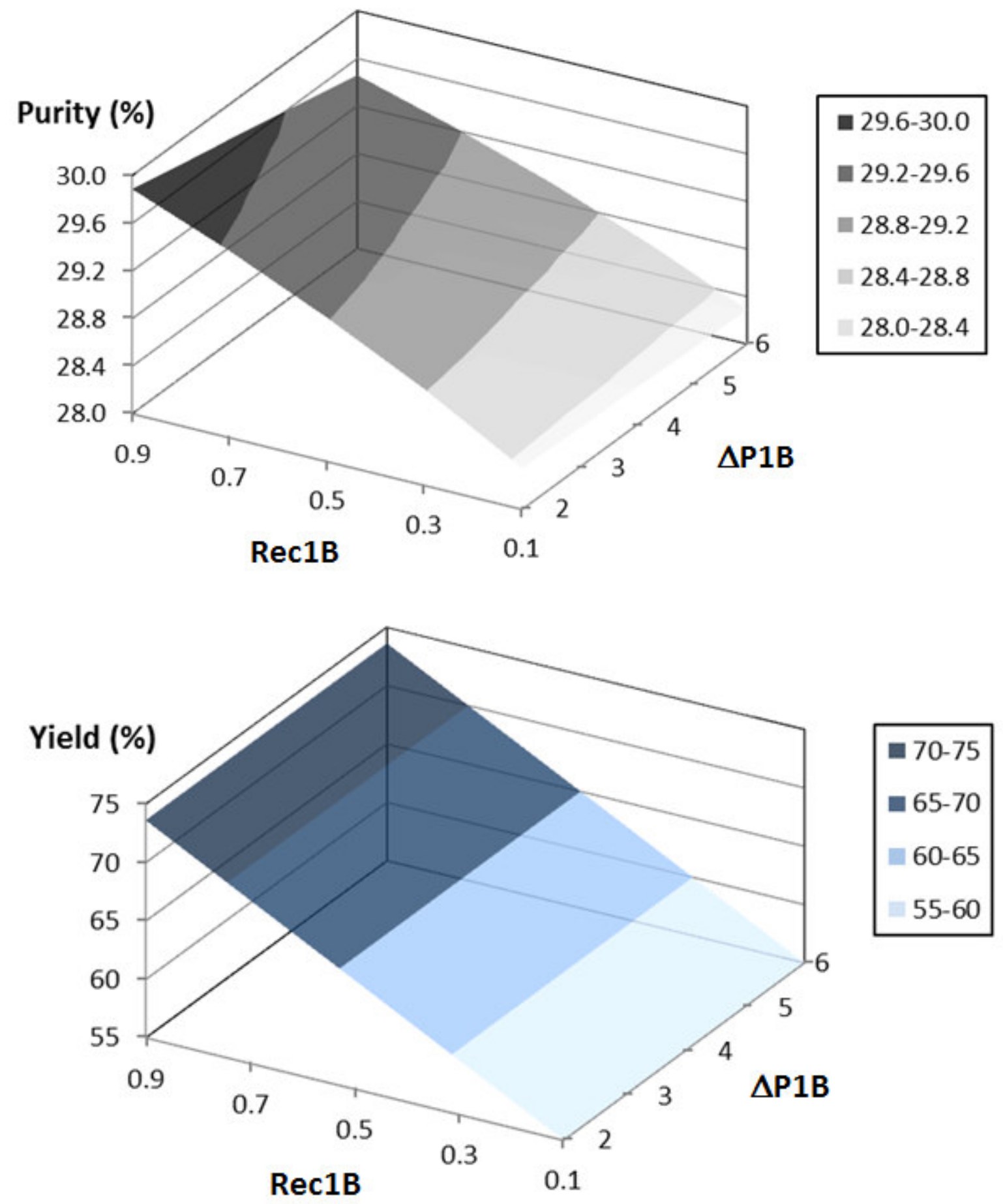

Figure 7 

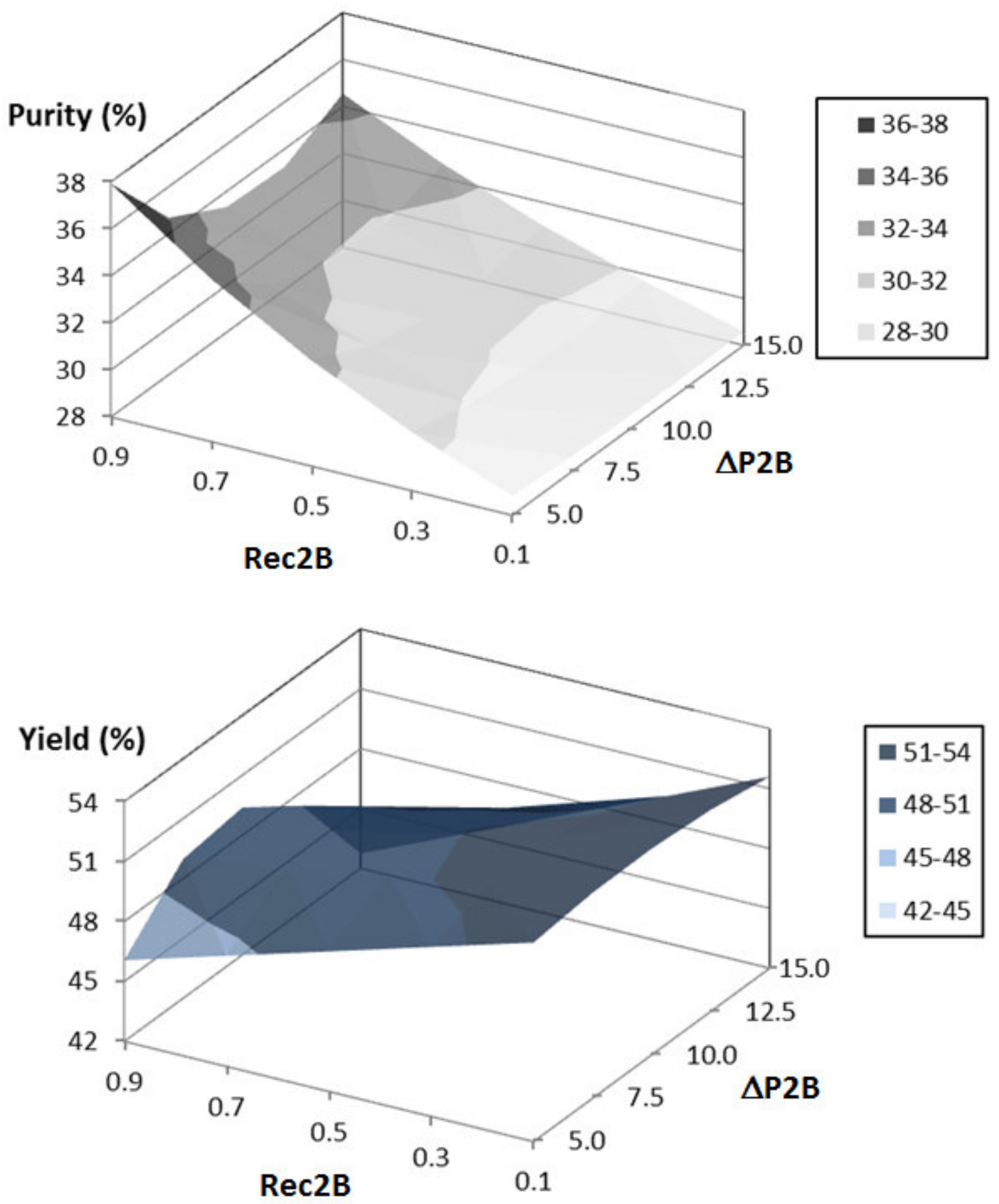

Figure 8 


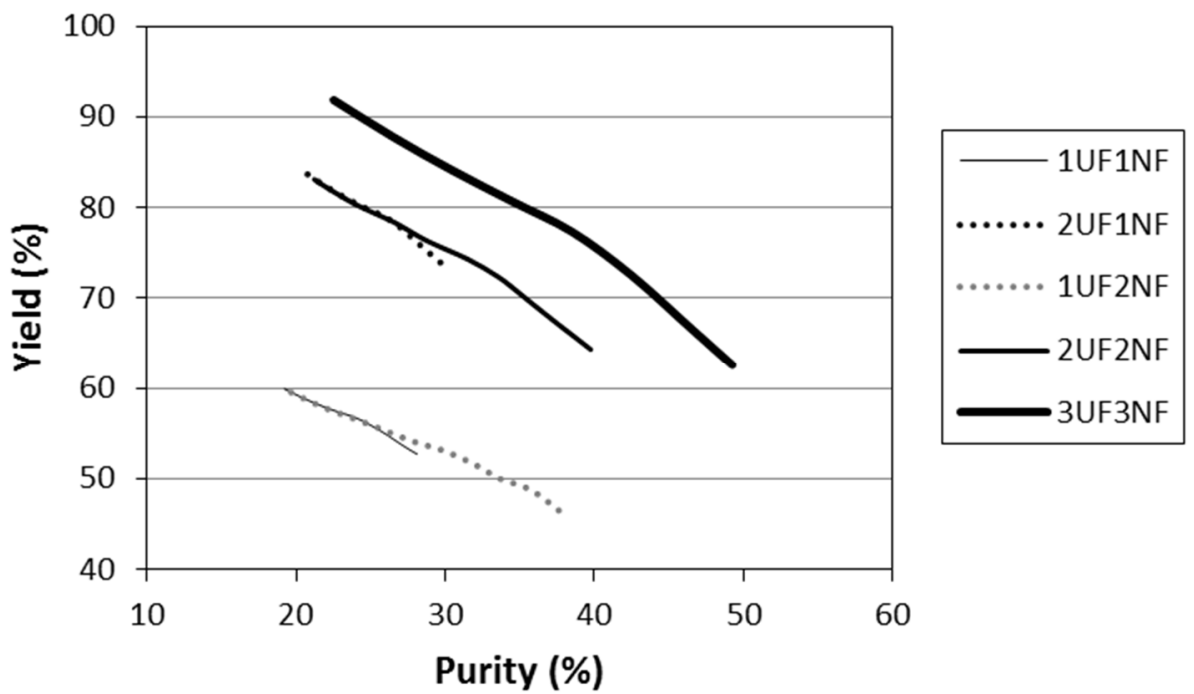

Figure 9 
Table 1

Peptide Fractions Molecular weight range (kDa) Protein distribution (\%)

UltraHeavy (UH)

Heavy $(\mathrm{H})$

Medium (M)

$>7.0$

11.5

Light (L)

$4.0-7.0$

3.0

UltraLight (UL)

$1.0-4.0$

19.0

$0.3-1.0$

28.5

$<0.3$

38.0 
Table 2

\begin{tabular}{ccc}
\hline \multirow{2}{*}{ Peptide Fractions } & \multicolumn{2}{c}{ Rejections (\%) } \\
\cline { 2 - 3 } & UF Membrane & NF Membrane \\
\hline UH & 100 & 100 \\
H & $96-7.75(\Delta \mathrm{P})$ & 100 \\
M & 33 & $-0.42(\Delta \mathrm{P})^{2}+7.7(\Delta \mathrm{P})+58$ \\
L & 21 & $-0.64(\Delta \mathrm{P})^{2}+13(\Delta \mathrm{P})+15$ \\
UL & 16 & $-0.76(\Delta \mathrm{P})^{2}+16(\Delta \mathrm{P})-28$ \\
\hline
\end{tabular}


Table 3

\begin{tabular}{|c|c|c|c|c|c|c|c|c|c|c|}
\hline & \multicolumn{2}{|c|}{ 1UF1NF } & \multicolumn{2}{|c|}{ 2UF1NF } & \multicolumn{2}{|c|}{ 1UF2NF } & \multicolumn{2}{|c|}{ 2UF2NF } & \multicolumn{2}{|c|}{ 3UF3NF } \\
\hline & $\begin{array}{l}\text { Maximal } \\
\text { purity }\end{array}$ & $\begin{array}{l}\text { Maximal } \\
\text { yield }\end{array}$ & $\begin{array}{l}\text { Maximal } \\
\text { purity }\end{array}$ & $\begin{array}{l}\text { Maximal } \\
\text { yield }\end{array}$ & $\begin{array}{l}\text { Maximal } \\
\text { purity }\end{array}$ & $\begin{array}{l}\text { Maximal } \\
\text { yield }\end{array}$ & $\begin{array}{l}\text { Maximal } \\
\text { purity }\end{array}$ & $\begin{array}{l}\text { Maximal } \\
\text { yield }\end{array}$ & $\begin{array}{l}\text { Maximal } \\
\text { purity }\end{array}$ & $\begin{array}{l}\text { Maximal } \\
\text { yield }\end{array}$ \\
\hline Purity (\%) & 28.1 & 19.2 & 29.9 & 20.8 & 37.9 & 19.7 & 39.8 & 21.2 & 49.3 & 22.5 \\
\hline Yield (\%) & 52.7 & 59.9 & 73.6 & 83.7 & 46.1 & 59.5 & 64.4 & 83.1 & 62.6 & 91.9 \\
\hline$\Delta P_{1 A}$ (bar) & 2.00 & 2.00 & 2.00 & 2.00 & 2.00 & 2.00 & 2.00 & 2.00 & 2.00 & 2.00 \\
\hline$\Delta \mathrm{P}_{1 \mathrm{~B}}$ (bar) & - & - & 2.00 & 2.00 & - & - & 2.00 & 2.00 & 2.00 & 2.00 \\
\hline$\Delta P_{1 c}$ (bar) & - & - & - & - & - & - & - & - & 2.00 & 2.00 \\
\hline$\Delta \mathrm{P}_{2 \mathrm{~A}}$ (bar) & 5.00 & 9.17 & 5.00 & 9.17 & 5.00 & 9.17 & 5.00 & 9.17 & 5.00 & 9.17 \\
\hline$\Delta \mathrm{P}_{2 \mathrm{~B}}$ (bar) & - & - & - & - & 5.00 & 9.17 & 5.00 & 9.17 & 5.00 & 9.17 \\
\hline$\Delta \mathrm{P}_{2 \mathrm{C}}$ (bar) & - & - & - & - & - & - & - & - & 5.00 & 9.17 \\
\hline $\operatorname{Rec}_{1 \mathrm{~A}}$ & 0.90 & 0.90 & 0.90 & 0.90 & 0.90 & 0.90 & 0.90 & 0.90 & 0.90 & 0.90 \\
\hline $\operatorname{Rec}_{1 \mathrm{~B}}$ & - & - & 0.90 & 0.90 & - & - & 0.90 & 0.90 & 0.90 & 0.90 \\
\hline $\operatorname{Rec}_{1 \mathrm{C}}$ & - & 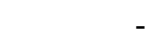 & & & _ & - & & & 0.90 & 0.90 \\
\hline $\operatorname{Rec}_{2 A}$ & 0.90 & 0.10 & 0.90 & 0.10 & 0.90 & 0.10 & 0.90 & 0.10 & 0.90 & 0.10 \\
\hline $\operatorname{Rec}_{2 B}$ & - & - & - & - & 0.90 & 0.10 & 0.90 & 0.10 & 0.90 & 0.10 \\
\hline $\operatorname{Rec}_{2 \mathrm{C}}$ & - & - & - & - & - & - & - & - & 0.90 & 0.10 \\
\hline $\begin{array}{c}\text { Total membrane } \\
\text { area }\left(\mathrm{m}^{2}\right)\end{array}$ & 62.2 & 12.6 & 48.8 & 19.7 & 76.4 & 13.3 & 68.4 & 20.8 & 92.7 & 28.7 \\
\hline
\end{tabular}


Table 4

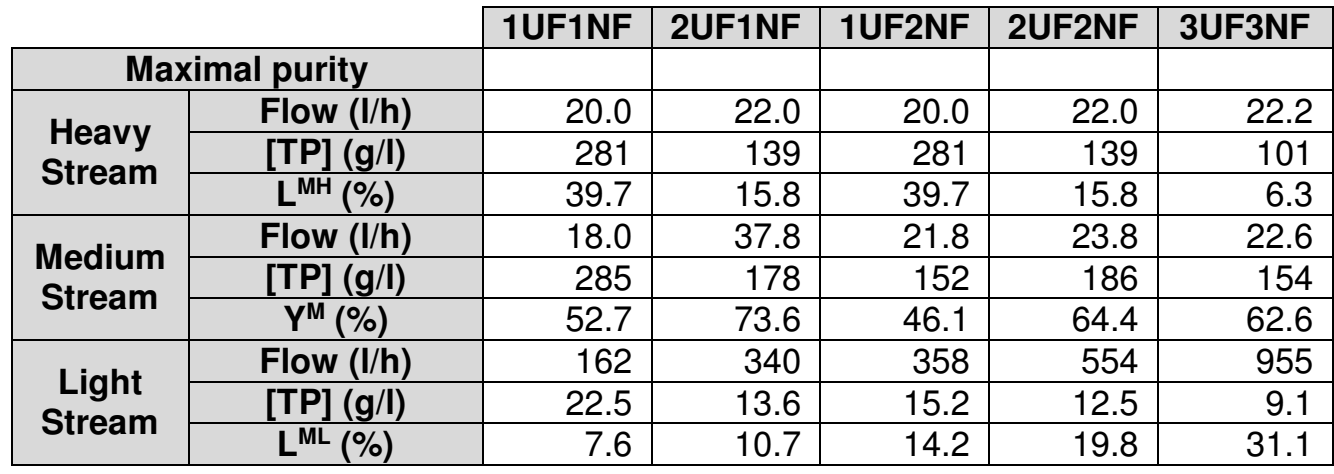

\begin{tabular}{|c|c|c|c|c|c|c|}
\hline \multicolumn{7}{|c|}{ Maximal yield } \\
\hline \multirow{3}{*}{$\begin{array}{l}\text { Heavy } \\
\text { Stream }\end{array}$} & Flow (l/h) & 20.0 & 22.0 & 20.0 & 22.0 & 22.2 \\
\hline & [TP] $(g / l)$ & 281 & 139 & 281 & 139 & 101 \\
\hline & $\mathrm{L}^{\mathrm{MH}}(\%)$ & 39.7 & 15.8 & 39.7 & 15.8 & 6.3 \\
\hline \multirow{3}{*}{$\begin{array}{c}\text { Medium } \\
\text { Stream }\end{array}$} & Flow (I/h) & 162 & 340 & 326 & 486 & 763 \\
\hline & [TP] (g/l) & 52.6 & 32.4 & 25.4 & 22.1 & 14.6 \\
\hline & $Y^{M}(\%)$ & 59.9 & 83.7 & 59.5 & 83.1 & 91.9 \\
\hline \multirow{3}{*}{$\begin{array}{l}\text { Light } \\
\text { Stream }\end{array}$} & Flow (I/h) & 18.0 & 37.8 & 54.2 & 91.8 & 215 \\
\hline & [TP] $(g / l)$ & 14.2 & 8.5 & 9.2 & 6.9 & 4.6 \\
\hline & $L^{M L}(\%)$ & 0.4 & 0.5 & 0.8 & 1.1 & 1.8 \\
\hline
\end{tabular}




\begin{tabular}{|c|c|c|c|c|c|c|}
\hline & \multicolumn{5}{|c|}{ Protein fraction content (\%) } \\
\hline & & UH & $\mathrm{H}$ & $\mathbf{M}$ & $\mathbf{L}$ & UL \\
\hline \multicolumn{7}{|c|}{ Maximal purity } \\
\hline \multirow{3}{*}{ 1UF1NF } & Heavy Stream & 29.5 & 6.3 & 19.3 & 21.1 & 23.8 \\
\hline & Medium Stream & 0.0 & 1.5 & 28.1 & 38.4 & 32.0 \\
\hline & Light Stream & 0.0 & 0.0 & 5.7 & 25.9 & 68.4 \\
\hline \multirow{3}{*}{ 2UF1NF } & Heavy Stream & 54.3 & 9.6 & 14.1 & 11.2 & 10.7 \\
\hline & Medium Stream & 0.0 & 2.1 & 29.9 & 37.7 & 30.3 \\
\hline & Light Stream & 0.0 & 0.0 & 6.3 & 26.4 & 67.3 \\
\hline \multirow{3}{*}{ 1UF2NF } & Heavy Stream & 29.5 & 6.3 & 19.3 & 21.1 & 23.8 \\
\hline & Medium Stream & 0.0 & 2.3 & 37.9 & 40.2 & 19.6 \\
\hline & Light Stream & 0.0 & 0.0 & 7.2 & 29.0 & 63.9 \\
\hline \multirow{3}{*}{ 2UF2NF } & Heavy Stream & 54.3 & 9.6 & 14.1 & 11.2 & 10.7 \\
\hline & Medium Stream & 0.0 & 3.1 & 39.8 & 38.8 & 18.3 \\
\hline & Light Stream & 0.0 & 0.0 & 7.9 & 29.5 & 62.6 \\
\hline \multirow{3}{*}{ 3UF3NF } & Heavy Stream & 73.7 & 10.8 & 7.6 & 4.4 & 3.5 \\
\hline & Medium Stream & 0.0 & 5.5 & 49.3 & 35.6 & 9.7 \\
\hline & Light Stream & 0.0 & 0.0 & 9.8 & 31.9 & 58.3 \\
\hline
\end{tabular}

\begin{tabular}{|c|c|r|r|r|r|r|}
\hline \multicolumn{2}{|l|}{ Maximal yield } & & & & & \\
\hline \multirow{3}{*}{ 1UF1NF } & Heavy Stream & 29.5 & 6.3 & 19.3 & 21.1 & 23.8 \\
\cline { 2 - 7 } & Medium Stream & 0.0 & 0.9 & 19.2 & 33.6 & 46.3 \\
\cline { 2 - 7 } & Light Stream & 0.0 & 0.0 & 4.3 & 22.4 & 73.3 \\
\hline \multirow{3}{*}{ 2UF1NF } & Heavy Stream & 54.3 & 9.6 & 14.1 & 11.2 & 10.7 \\
\cline { 2 - 7 } & Medium Stream & 0.0 & 1.3 & 20.8 & 33.4 & 44.5 \\
\cline { 2 - 7 } & Light Stream & 0.0 & 0.0 & 4.8 & 22.9 & 72.3 \\
\hline \multirow{3}{*}{ 1UF2NF } & Heavy Stream & 29.5 & 6.3 & 19.3 & 21.1 & 23.8 \\
\cline { 2 - 7 } & Medium Stream & 0.0 & 0.9 & 19.7 & 33.9 & 45.6 \\
\cline { 2 - 7 } & Light Stream & 0.0 & 0.0 & 4.4 & 22.6 & 72.9 \\
\hline \multirow{3}{*}{ 2UF2NF } & Heavy Stream & 54.3 & 9.6 & 14.1 & 11.2 & 10.7 \\
\cline { 2 - 7 } & Medium Stream & 0.0 & 1.3 & 21.2 & 33.7 & 43.8 \\
\cline { 2 - 7 } & Light Stream & 0.0 & 0.0 & 4.9 & 23.1 & 72.0 \\
\hline \multirow{3}{*}{ 3UF3NF } & Heavy Stream & 73.7 & 10.8 & 7.6 & 4.4 & 3.5 \\
\cline { 2 - 7 } & Medium Stream & 0.0 & 1.7 & 22.5 & 33.7 & 42.0 \\
\cline { 2 - 7 } & Light Stream & 0.0 & 0.0 & 5.3 & 23.6 & 71.3 \\
\hline
\end{tabular}




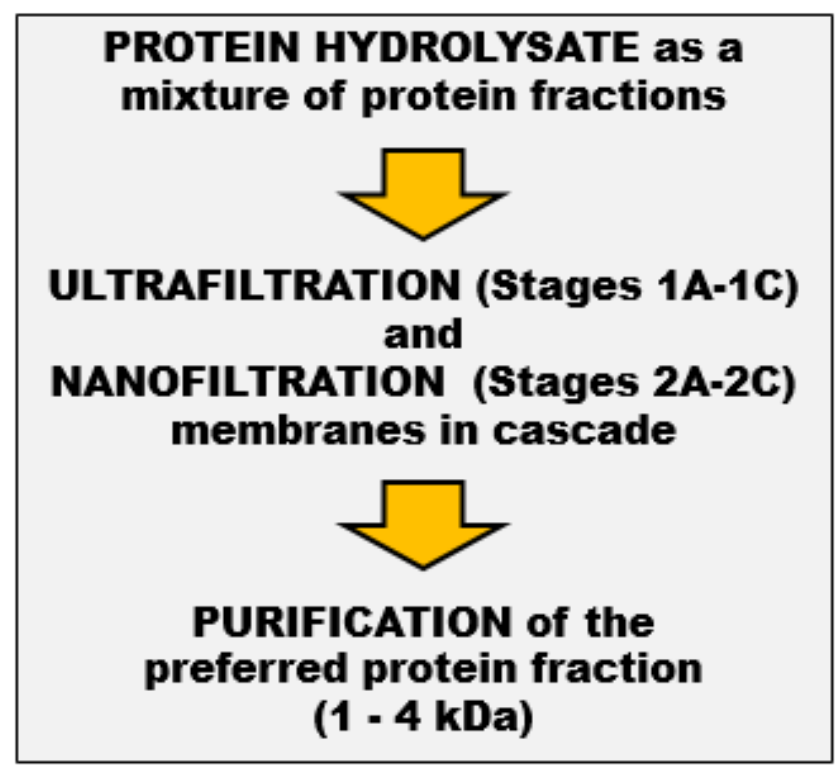

Preferred fraction purity: $19.0 \%$

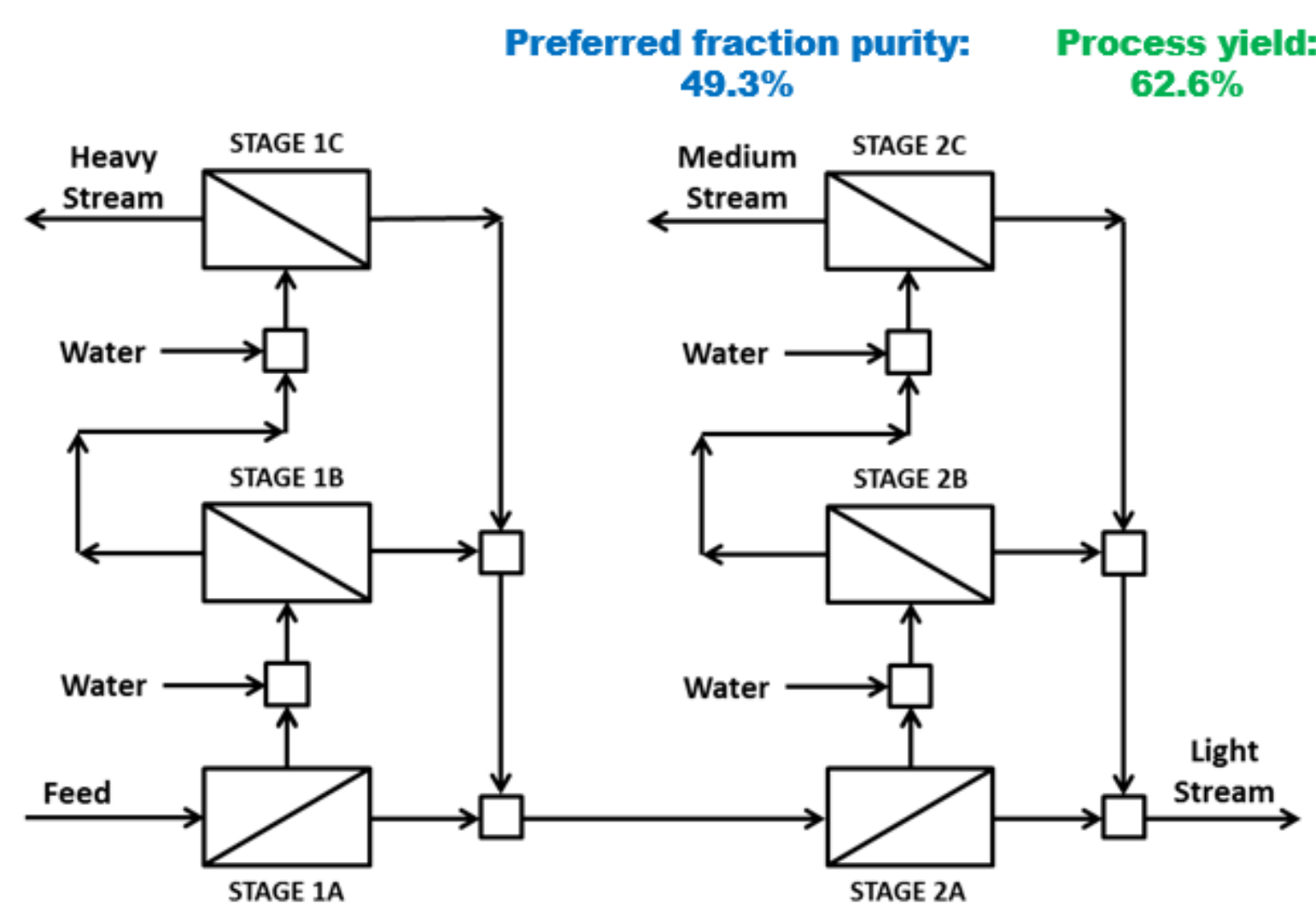

